\title{
Strength, Hydraulic, and Microstructural Characteristics of Expansive Soils Incorporating Marble Dust and Rice Husk Ash
}

\author{
Fazal E. Jalal $\mathbb{D},{ }^{1}$ Sultani Mulk, ${ }^{2}$ Shazim Ali Memon $\mathbb{D D}^{3}$ Babak Jamhiri $\mathbb{D},{ }^{1}$ \\ and Ahsan Naseem (iD ${ }^{4}$ \\ ${ }^{1}$ Department of Civil Engineering, Shanghai Jiao Tong University, Shanghai, China \\ ${ }^{2}$ Department of Civil Engineering, COMSATS University Islamabad, Abbottabad, Pakistan \\ ${ }^{3}$ Department of Civil and Environmental Engineering, School of Engineering and Digital Sciences, Nazarbayev University, \\ Nur-Sultan, Kazakhstan \\ ${ }^{4}$ Department of Civil Engineering, University of Ghent, Technologiepark Zwijnaarde, Ghent, Belgium
}

Correspondence should be addressed to Fazal E. Jalal; jalal2412@sjtu.edu.cn and Shazim Ali Memon; shazim.memon@nu.edu.kz

Received 30 April 2021; Revised 22 July 2021; Accepted 22 October 2021; Published 12 November 2021

Academic Editor: Youjun Ning

Copyright ( $\odot 2021$ Fazal E. Jalal et al. This is an open access article distributed under the Creative Commons Attribution License, which permits unrestricted use, distribution, and reproduction in any medium, provided the original work is properly cited.

\begin{abstract}
Expansive/swell-shrink soils exhibit high plasticity and low strength, which lead to settlement and instability of lightly loaded structures. These problematic soils contain various swelling clay minerals that are unsuitable for engineering requirements. In an attempt to counter the treacherous damage of such soils in modern geotechnical engineering, efforts are underway to utilize environmentally friendly and sustainable waste materials as stabilizers. This study evaluates the strength and consolidation characteristics of expansive soils treated with marble dust (MD) and rice husk ash (RHA) through a multitude of laboratory tests, including consistency limits, compaction, uniaxial compression strength (UCS), and consolidation tests. By using X-ray diffraction (XRD) and scanning electron microscopy (SEM) analyses, the effect of curing on UCS after 3, 7, 14, 28, 56, and 112 days was studied from the standpoint of microstructural changes. Also, the long-term strength development of treated soils was analyzed in terms of the interactive response of impacting factors with the assistance of a series of ANN-based sensitivity analyses. It is found from the results that the addition of MD and RHA lowered down the water holding capacity, thereby causing a reduction in soil plasticity (by $21 \%$ for $\mathrm{MD}$ and $14.5 \%$ for RHA) and optimum water content (by $2 \%$ for $\mathrm{MD}$ and increased by $6 \%$ for RHA) along with an increase in the UCS (for 8\% MD from $97 \mathrm{kPa}$ to $471 \mathrm{kPa}$ and for $10 \%$ RHA from $211 \mathrm{kPa}$ to $665 \mathrm{kPa}$, after 3 days and 112 days of curing, respectively). Moreover, from the oedometer test results, $m_{v}$ initially increased up to $6 \%$ dosage and then dropped with further increase in the preconsolidation pressure. Furthermore, the compression index dropped with an increase in the preconsolidation pressure and addition of MD/RHA, while the coefficient of permeability $(k)$ of RHA stabilized soil was higher than that of MD-treated samples for almost all dosage levels. The formation of the fibrous cementitious compounds (CS-H; C-A-H) increased at optimum additive dosage after 7 days and at higher curing periods. Hence, the use of $10 \%$ RHA and $12 \%$ $\mathrm{MD}$ as replacement of the expansive soil is recommended for higher efficacy. This research would be helpful in reducing the impacts created by the disposal of both expansive soil and industrial and agricultural waste materials.
\end{abstract}

\section{Introduction}

Expansive soils or soft soils are hydrophilic due to the presence of water-sensitive clay minerals resulting from environmental and seasonal moisture variations, which cause myriad problems in civil engineering works. They are highly problematic and cause annual economic loss ranging from several millions to billions of dollars, thus exceeding damage caused by other geological disasters [1-5]. Soft expansive clays are extremely sticky when they are wet and are as hard as a rock when they are in a dry state, thus rendering their compaction to be cumbersome $[6,7]$. These swelling soils are prevalent across the globe, covering approximately $33 \%$ area of Sudan, $20 \%$ of both Indonesia and India, $12 \%$ region of Syria, and approximately $6 \%$ of China [8]. Such soils are abundantly present in various Asian regions, including Pakistan, Saudi Arabia, Iran, Malaysia, and Oman, and their presence significantly impedes the 
construction work and causes long-term stability problems $[9,10]$. They exhibit a higher affinity for moisture; that is, they swell upon water uptake and shrink when water dissipates $[7,11]$. In some cases, the volume rises up to three or even more times the original volume, thus exerting a swelling pressure on overlying foundation structures [12], which results in crack development of the foundations of residential buildings, highways and airfield pavements, and underground utilities $[13,14]$; particularly, the lightly loaded structures undergo excessive damage near the ground surface [15].

The expansive soils are stabilized by assessing a variety of additives as "green stabilizer" [16], which have long been incorporated for improving their engineering and microstructural behavior by other researchers: lime [17], cement [18], fly ash [19], rice husk ash [20-23], waste ceramic dust [24-26], nanosilica [27, 28], calcium carbide residue [29], microbial biopolymers [30,31], and so on. Of these, lime and cement are more commonly used additives in pavements construction and lightly loaded infrastructure. However, the effectiveness of lime as well as cement in soils containing sulfates $\left(\mathrm{SO}_{4}\right)$ is poor [32]. In addition, these stabilizers impart brittleness to soils, which is highly undesirable in dynamic loading conditions in case of pavements [11]. Mostly, the soil stabilizers are broadly grouped into three major categories: (i) traditional additives (e.g., $\mathrm{CaO}$ and cement), (ii) by-product additives (marble dust, cement kiln dust such as CKD, and fly ash), and (iii) nontraditional additives (e.g., ammonium compounds, sulfonated oils, and polymers) [7, 33].

The inevitable problem of handling industrial and agricultural waste on the global level is a serious challenge. These wastes could be incorporated either alone or in conjunction with other chemical agents for ameliorating the soil characteristics in order to vilify their negative environmental impacts and to achieve sustainability $[34,35]$. The scope of this study is limited to the selection of marble dust (MD) and rice husk ash (RHA) owing to their indigenous availability. MD sludge is produced in large quantity, which is openly landfilled, thus leading to environmental damage and health risks. Positive results have been achieved in the construction industry when it was incorporated in soil, bricks, production of cement, concrete, and so on [36-38]. After performing a multitude of consolidated undrained triaxial compression on recycled tire treated-cement treated samples at 7, 14, and 28 days of curing, it was found that the undrained shear strength parameters improved significantly due to the formation of cementation compounds [39]. Demolished tile material improved the plasticity index and $\mathrm{pH}$ of soft soil, and its addition lowered down the water holding capacity, while the maximum dry density was recorded to be increased by almost 10\% [40]. Furthermore, Firat et al. [37] used marble dust in soil stabilization for road construction where the medium to low plasticity soil was used as road base filling material. The tests results on the samples treated with up to $15 \%$ marble content and cured for 112 days indicated an increased amount of Tobermorite, thereby increasing the compression strength. These results are encouraging and show that marble dust utilization can be a viable option concerning the environmental aspect. In addition, the replacement of $\mathrm{MD}$ in concrete has yielded cost-effectiveness and sustainability [41, 42]. On the other hand, rice husk is a widely used agriculture waste in the ricemilling process that transforms to RHA upon burning and contains a high amount of amorphous silica. When the RHA reacts with calcium hydroxide, they generate cementitious gels, which helps to improve the compression strength of soil $[21,43,44]$. It has been established from previous studies that RHA is a very reactive pozzolanic material, and it can efficaciously stabilize high plastic expansive soils either solely or in combination with lime and/or other additives $[45,46]$. Unfortunately, the raw agricultural waste materials and industrial effluents are usually disposed of openly over land or inside the water bodies [47]. Such waste materials must be handled with great care in order to attain a green environment. However, the chemical soil stabilization of expansive soils has largely been in practice across many countries $[33,48]$; this technique is less commonly brought to practice in the developing countries of Asia. To the authors' knowledge, no study to date is available explaining the independent roles of locally produced marble waste and rice husk ash on the compression strength and consolidation behavior of clays with high plasticity cured for long curing periods in the context of microstructural tests. Therefore, the objective of this study is to analyze the effect of long-term curing on the mechanical and morphological performance of expansive soil using marble dust/rice husk ash. An extensive laboratory soil testing was performed to evaluate the index properties (consistency limits) and engineering properties (compaction, compression strength, and consolidation) of the soil with varying quantities of additives, and the long-term strength development of treated soils was analyzed in terms of the interactive response of impacting factors with assistance of ANN-based sensitivity analysis. In addition, the change in microstructural features and morphology was studied by scanning electron microscopy (SEM) and X-ray diffraction (XRD) analysis.

\section{Site Location}

The study area is located in Nandipur town $\left(32^{\circ} 15^{\prime} 22^{\prime \prime} \mathrm{N}\right.$ $74^{\circ} 15^{\prime} 50^{\prime \prime}$ E) of Gujranwala city, Pakistan, with an elevation of 225 to $231 \mathrm{~m}$, from where expansive soil specimens were obtained (Figure 1). The region is susceptible to natural and artificial slope instability. Preliminary investigation of the area revealed the diagonal cracking of boundary walls and the presence of polygonal desiccation cracks over the inclined face of embankments running along the pavements that could be attributed to the swelling of the expansive soil, as shown in Figures 2(a) and 2(b).

\section{Experimental Investigation}

3.1. Test Materials. For collection of soil specimens, trial pits were excavated, and $25 \mathrm{~kg}$ of disturbed expansive soil was obtained (Figure 2(c)). The physical characteristics of the soil specimen such as specific gravity $\left(G_{\mathrm{s}}\right)$, optimum moisture content (OMC), Atterberg limits, particle size, and the 


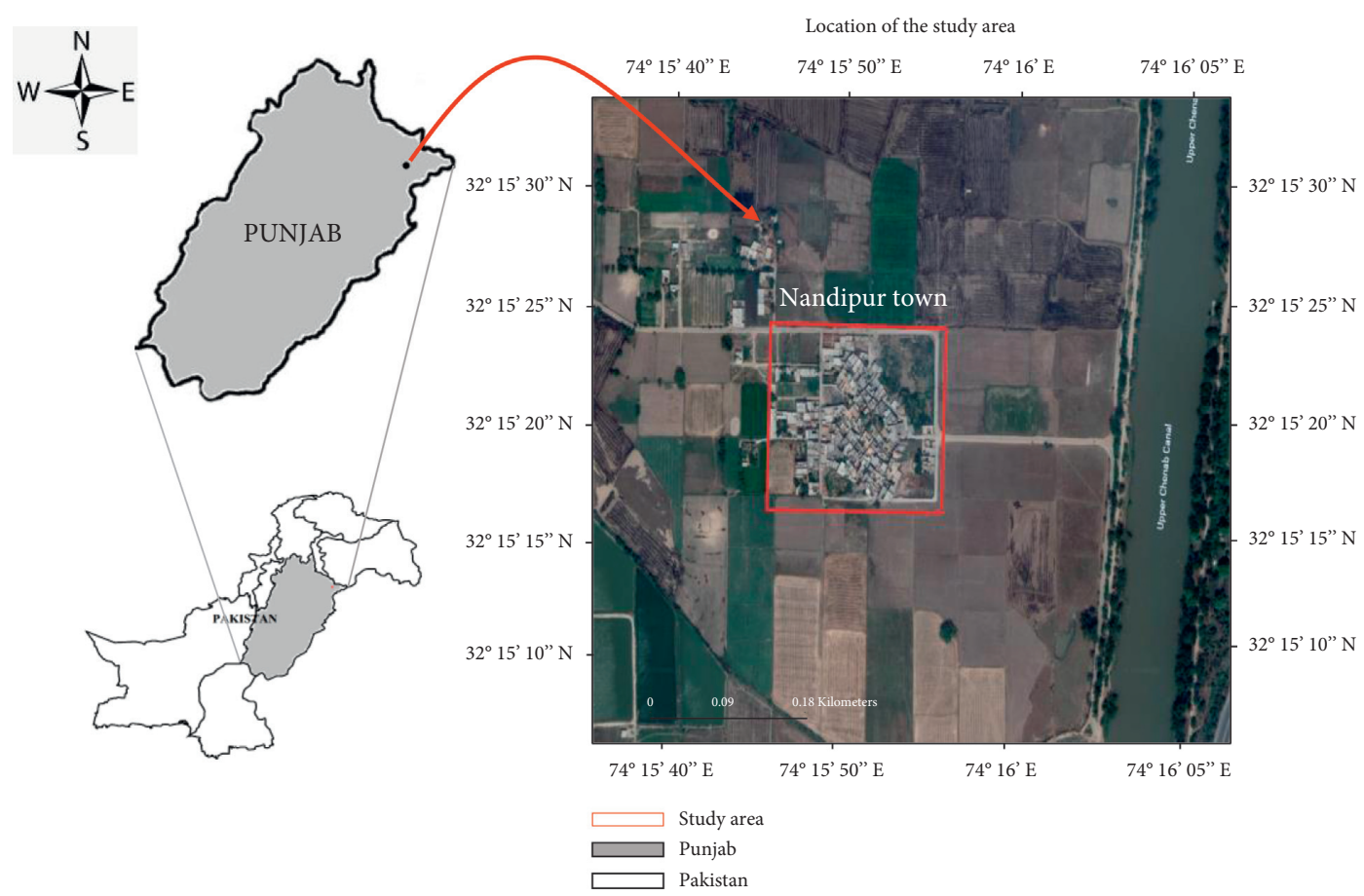

Figure 1: Location of the study area (highlighted).

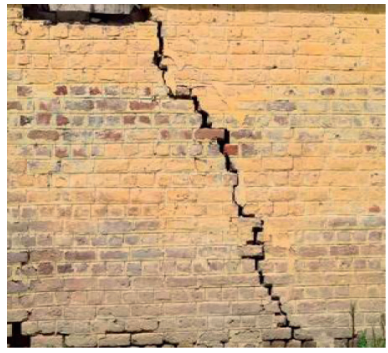

(a)

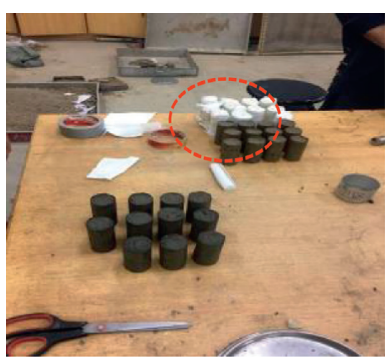

(d)

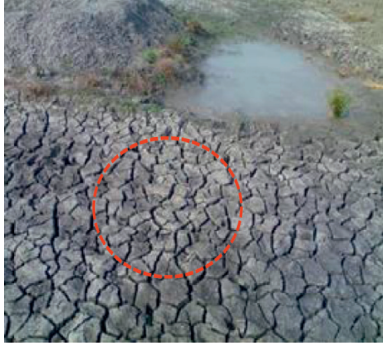

(b)

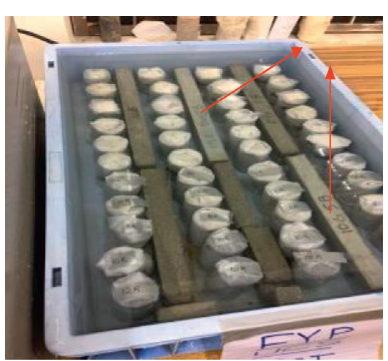

(e)

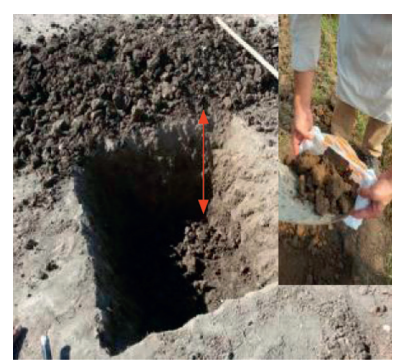

(c)

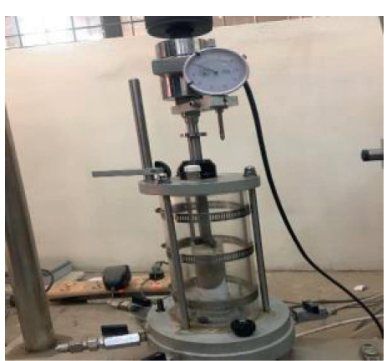

(f)

Figure 2: Continued. 


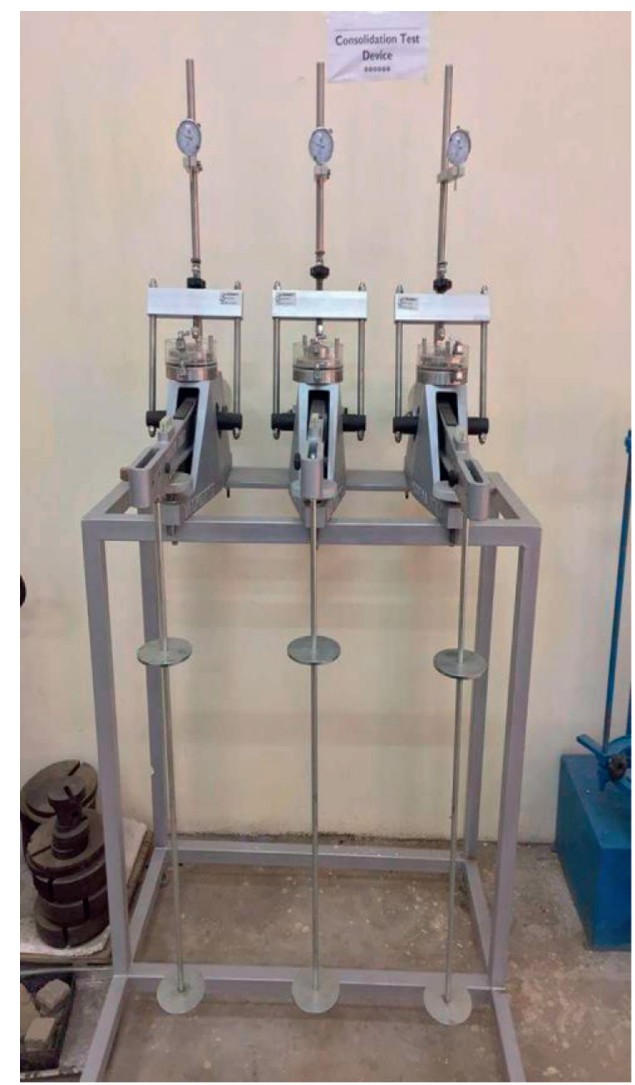

(g)

FIGURE 2: Brief overview of site sampling, specimen preparation, and laboratory testing. (a) Diagonal crack in boundary wall. (b) Prevalence of desiccation cracks. (c) $1.5 \mathrm{~m} \times 1.5 \mathrm{~m}$ excavated pit. (d) UCS samples prepared for curing. (e) Samples cured (7, 14, 18, 56, and 112 days). (f) UCS machine (Modena, Italy). (g) Oedometer test assembly (Modena, Italy).

maximum dry density (MDD) were determined in accordance with designated ASTM standards D-698, D-2216, D-4318, D-854, and D-6913, respectively, shown in Table 1. From the particle size analysis (Figure 3), it is clear that the soil is composed of approximately $78 \%$ fines. Therefore, based on plasticity characteristics, it can be classified as $\mathrm{CH}$ according to the unified soil classification system (USCS). In addition, Table 1 contains some of the index and engineering properties, whereas Table 2 contains the oxides' composition by X-ray fluorescence (XRF) test for the soil and twin additives considered for this study.

The crystalline structure of the minerals of the expansive soil, $\mathrm{MD}$, and RHA was identified by X-ray diffraction (XRD) (Figure 4) using a diffractometer (Model: JDX-2532) operating at voltage 20 to $40 \mathrm{kV}$ with $\mathrm{X}$-rays from Cu-anode at a wavelength of $1.54128 \mathrm{~A}^{\circ}$. The results revealed that soil contained muscovite $\left(\mathrm{KAl}_{2}\left(\mathrm{AlSi}_{3} \mathrm{O}_{10}\right)(\mathrm{F}, \mathrm{OH})_{2}\right)$, montmorillonite $\left(\mathrm{Al}_{2} \mathrm{H}_{2} \mathrm{Na}_{2} \mathrm{O}_{13} \mathrm{Si}_{4}\right)$, and albite $\left(\mathrm{NaAlSi}_{3} \mathrm{O}_{8}\right)$, alongside the presence of plagioclase and the dominant nonclay mineral, that is, quartz $\left(\mathrm{SiO}_{2}\right)$. MD exhibits a high amount of calcite with distinct corresponding peaks and some traces of dolomite along with the presence of quartz, while the RHA shows the presence of excess amorphous silica.

The main ingredient observed in $\mathrm{MD}$ is calcium carbonate $\left(\mathrm{CaCO}_{3}\right)$; therefore, the marble waste contains abundant $\mathrm{CaO}$ (49.9\%) and significant loss on ignition (LOI) values [49]. Results of XRF for MD are similar to those reported by past researchers $[42,49,50]$, indicating that MD exhibits higher crystalline nature and lesser cementitious nature. In addition, the combined percentage of alumina, silica, and lime falls below 70\%, so it is expected that MDtreated soils would improve the engineering properties due to filling and nucleation. The densification of modified soil matrix by virtue of filling of MD particles would enhance the density and compression strength.

RHA studied in this paper was greyish black, which suggests that carbon content has undergone partial burning. According to the XRF analysis, the $\mathrm{SiO}_{2}$ content is higher in RHA, and the combined percentage of alumina, silica, and calcium oxide totals $78.66 \%$ (exceeding $70 \%$, benchmark set by ASTM) which conforms to the requirements of pozzolanic material as per ASTM D4943 standard. Therefore, the pozzolanic nature of RHA would play a major role in improving the properties of expansive soils.

After collection, the waste sludge of marble was ovendried at $110 \pm 5^{\circ} \mathrm{C}$ until a uniform weight was obtained and then pulverized using a rubber pestle hammer. On the contrary, RHA was sieved using the $425 \mu \mathrm{m}$ so that mixing with clay and compaction becomes convenient. 
TABLE 1: Index properties and geotechnical characteristics of soil, marble dust, and rice husk ash.

\begin{tabular}{|c|c|c|c|c|c|}
\hline Geotechnical properties & Unit & Soil & $\mathrm{MD}$ & RHA & Standard designation \\
\hline Liquid limit, LL & $\%$ & 54.24 & 89.20 & 90.34 & ASTM D 4318-00 \\
\hline Plastic limit, PL & $\%$ & 18.11 & 32.96 & 32.67 & ASTM D 4318-00 \\
\hline Plastic index, PI & $\%$ & 36.13 & 56.24 & 67.67 & ASTM D 4318-00 \\
\hline Shrinkage limit, SL & $\%$ & 8.2 & 13.27 & 17.01 & ASTM D4943 - 18 \\
\hline Specific gravity, $G_{s}$ & - & 2.54 & 2.17 & 2.01 & ASTM D854-02 \\
\hline Silt and clay & $\%$ & $22.5+78$ & 45 & 40 & ASTM 98 D422-63 \\
\hline MDD & $\mathrm{kg} / \mathrm{m}^{3}$ & 16.99 & 15.44 & 14.93 & ASTM D698 \\
\hline OMC & $\%$ & 17.6 & 19.73 & 21.19 & ASTM D698 \\
\hline USCS & - & $\mathrm{CH}$ & Nonplastic & Nonplastic $^{\dagger}$ & ASTM D2487-00 \\
\hline Activity, $A$ & - & 0.93 & 0.36 & 0.42 & ASTM D2487-00 \\
\hline Permeability, $K$ & $\mathrm{~m} / \mathrm{s}$ & Impervious & 0.000034 & 0.00044 & ASTM D2435 \\
\hline UCS & $\mathrm{kPa}$ & 50 & - & - & ASTM D2166 \\
\hline
\end{tabular}

${ }^{\dagger}[21]$.

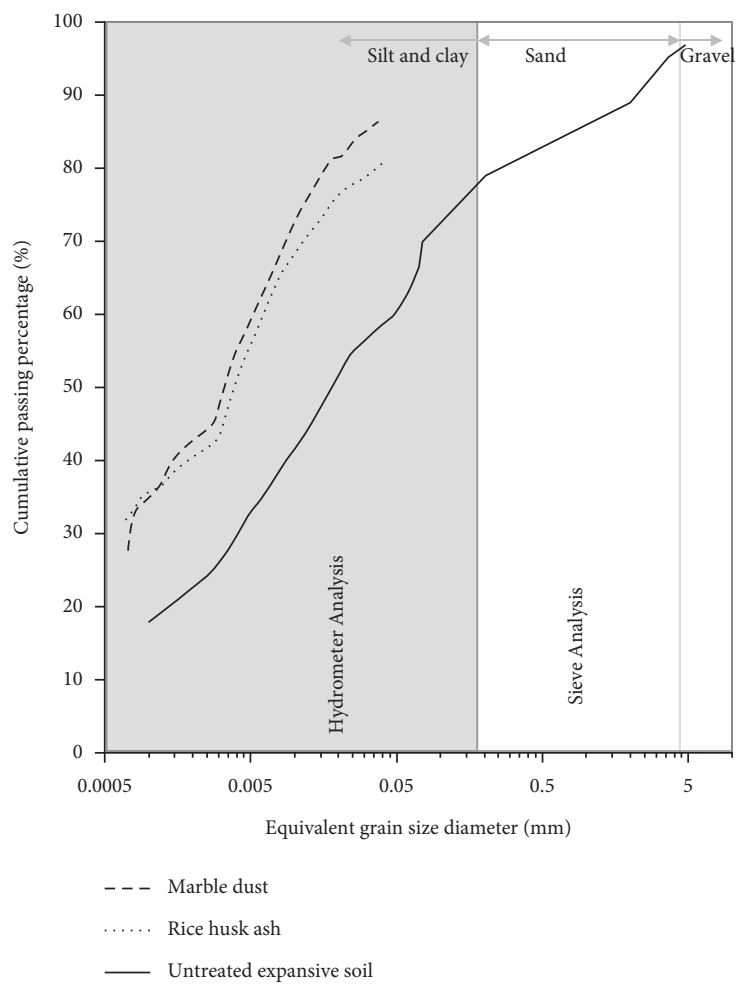

FIgURE 3: Particle size distribution curve of marble dust, rice husk ash, and expansive soil.

TABLE 2: Results of XRF analyses of expansive soil, marble dust, and rice husk ash.

\begin{tabular}{|c|c|c|c|c|c|c|c|c|c|c|c|c|}
\hline Oxide composition & $\mathrm{K}_{2} \mathrm{O}$ & $\mathrm{N}_{2} \mathrm{O}$ & $\mathrm{Al}_{2} \mathrm{O}_{3}$ & $\mathrm{CaO}$ & $\mathrm{MgO}$ & $\mathrm{SiO}_{2}$ & $\mathrm{MnO}$ & $\mathrm{Fe}_{2} \mathrm{O}_{3}$ & $\mathrm{TiO}_{2}$ & $\mathrm{P}_{2} \mathrm{O}_{5}$ & LOI & Total \\
\hline Soil (wt. \%) & 0 & 8.2 & 21 & 7.1 & 4.67 & 51.5 & 0 & 5.4 & 0.09 & 0 & 1.9 & 99.86 \\
\hline MD (wt.\%) & 0.2 & 0.81 & 1.58 & 49.9 & 1.25 & 1.22 & 0.01 & 1.28 & 0.01 & 0.02 & 43 & 99.28 \\
\hline RHA (wt.\%) & 5.22 & 1.29 & 14.77 & 6.10 & 5.47 & 57.79 & 0.05 & 1.97 & 0.24 & 2.01 & 4.6 & 99.6 \\
\hline
\end{tabular}

The RHA particles exhibit a high mass per unit weight, due to which the smaller particles could cause improper mixing [21]. Figure 3 suggests that cumulative passing percentage at equivalent grain size diameter of $0.002 \mathrm{~mm}$ is $45 \%$ and $40 \%$ for MD and RHA, respectively.
The curing duration of 112 days was selected to study the long-term curing effect on strength characteristics of stabilized soils [37]. Upon completion of every curing period, the specimens were tested according to nomenclature presented in Table 3. The number shows the dosage of the 


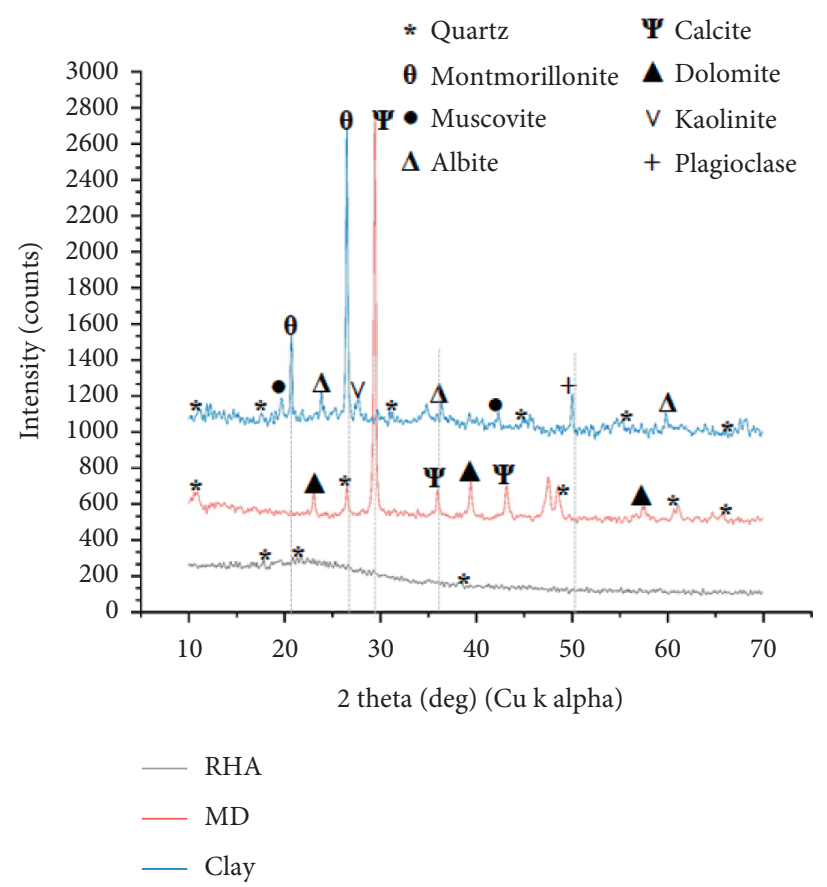

Figure 4: X-ray diffractographs of the expansive clay and stabilizer materials (marble dust and rice husk ash).

TABLE 3: Sample nomenclature with expansive soil, marble dust, and rice husk ash percentages.

\begin{tabular}{lccc}
\hline Sample code & Soil $(\%)$ & Marble dust (\%) & Rice husk ash (\%) \\
\hline ES-UT & 100 & 0 & 0 \\
ES-2M & 98 & 2 & 0 \\
ES-4M & 96 & 4 & 0 \\
ES-8M & 92 & 8 & 0 \\
ES-10M & 90 & 10 & 0 \\
ES-12M & 88 & 12 & 0 \\
ES-2R & 98 & 0 & 2 \\
ES-4R & 96 & 0 & 4 \\
ES-8R & 92 & 0 & 8 \\
ES-10R & 90 & 0 & 10 \\
ES-12R & 88 & 0 & 12 \\
\hline
\end{tabular}

respective stabilizer ( $M$ : marble dust; $R$ : rice husk ash), whereas ES and UT refer to "expansive soil" and "untreated" specimens, respectively. The results of each $\mathrm{MD} / \mathrm{RHA}$ mixture were compared with that of the untreated expansive soil (UT).

3.2. Tests Performed. Sieve and hydrometer analysis were performed to assess the gradation of soil, respectively. The hydrometer analysis was also conducted for both additives. The LL, PL, and SL tests were carried out on treated soil samples. The proctor compaction tests were conducted. The MDD and OMC were calculated from the compaction curves. The compression strength tests were conducted on ES-UT and the MD/RHA-treated soil. Consolidation characteristics were studied in detail by performing oedometer tests in a standard fixed ring consolidation apparatus, as shown in Figure 2(g). The ASTM standards of all the above-mentioned tests are listed in Table 1.
Firstly, in order to study the strength characteristics of treated soils, the MD and RHA were separately mixed in expansive soil by incorporating prefixed dosage levels of $4 \%$, $6 \%, 8 \%, 10 \%$, and $12 \%$, by dry weight of soil, as per designed methodology, to perform above-mentioned tests. The samples with prescribed MD/RHA ratios were also cured to study the effect of the curing period after $3,7,28,56,90$, and 112 days, as shown in Figures 2(d), 2(e), and 2(f).

Secondly, the consolidation characteristics obtained were coefficient of compressibility $\left(m_{v}\right)$, coefficient of consolidation $\left(c_{v}\right)$, preconsolidation pressure $\left(P_{c}\right)$, coefficient of compression $\left(C_{c}\right)$, and coefficient of permeability $(K)$. Equations (1) to (4) have been used to calculate $m_{v}, c_{v}$, $C_{\mathrm{c}}$ [51], and $k$ [52] values:

$$
m_{v}=\frac{\Delta \sigma}{\Delta e}\left(1+e_{0}\right)
$$

where $m_{v}$ is the coefficient of volume change, $\Delta \sigma$ is the pressure difference, and $\Delta e$ is the void ratio difference. 


$$
c_{v}=\frac{D^{2} T}{t_{90}},
$$

where $c_{v}$ is the coefficient of consolidation, $t_{90}$ refers to the time required for completing $90 \%$ degree of consolidation, and $T$ represents a constant time factor which is 0.848 for $90 \%$ of consolidation.

$$
C_{c}=\frac{e_{0}-e_{1}}{\log p_{0} / p_{1}},
$$

where $C_{c}$ is the compression index, $e_{0}$ and $e_{1}$ are the values of void ratios conforming to the consolidation pressure values of $P_{0}$ and $P_{1}$, respectively, and 0 and 1 indicate the interval of applied loading.

$$
k=c_{v} \times m_{v} \times \gamma_{w},
$$

where $k$ means the permeability measured in $(\mathrm{m} / \mathrm{s}), c_{v}$ refers to the coefficient of consolidation $\left(\mathrm{m}^{2} / \mathrm{s}\right), m_{v}$ is the coefficient of compressibility $\left(\mathrm{m}^{2} / \mathrm{kN}\right)$, and $\gamma_{w}$ is the specific weight of the soil $\left(\mathrm{kN} / \mathrm{m}^{3}\right)$.

\section{Results and Discussion}

4.1. Consistency Limits. Figures 5(a) and 5(b) show the results of LL, PL, and PI of the untreated and stabilized soil specimens mixed with varying quantities of MD/RHA. For a comparison reason, the results of lime and cement treatment have also been incorporated [18]. For the soil-MD mixture, the LL and PL decreased from $36 \%$ to $29 \%$ and $16 \%$ to $13 \%$, respectively, with $12 \%$ addition of $\mathrm{MD}$. The reduction in LL and PL beyond $8 \%$ dosage of MD was relatively higher. Subsequently, for $12 \% \mathrm{MD}$ blending of soil (ES-12M), the final PI indicates a reduction of $21 \%$ in comparison with untreated expansive soil (ES-UT). The reduction in PI upon $7 \%$ addition of lime is $48 \%$, which is twice more than ES$12 \mathrm{M}$ used in this study. However, the LL of soil treated with RHA uniformly decreased from $36 \%$ to $31 \%$ up to $10 \%$ dosage of $\mathrm{MD}$, while the addition of RHA has a negligible effect on PL, especially up to $10 \%$ addition of RHA. Further addition of RHA caused an increase in the LL. Hence, due to the increase of LL and reduction of PL from $10 \%$ to $12 \%$ RHA mixing, the final PI decreases to $14.5 \%$ at RHA addition of $10 \%$. On the contrary, the drastic drop in PI is almost threefold reaching $6 \%$ at cement addition of $5 \%$. Therefore, the addition of MD and RHA resulted in an overall reduction of the PI. The trend of Atterberg limits in case of cement is closer to that of RHA, as can be seen in Figure 5(b). Therefore, the decrease in PI is more for the RHA-blended soil in comparison with the MD-blended soil. Furthermore, to reduce the plasticity of soil, cement is considered the most efficacious additive, while MD is the least effective, as shown in Figure 5. These findings are in line with the results reported by [53].

For soil-RHA specimens, reduction in the PI is associated with the presence of light-weight RHA particles $\left(G_{s}=2.01\right)$, replacing the heavy expansive soil particles $\left(G_{s}=2.54\right)$ [54]. RHA is pozzolanic due to amorphous silica; therefore, the effect of RHA leads to the flocculation of particles. The RHA particles are adsorbed onto the soil particles that increase the aggregate interlocking, thus leading to a higher density of stabilized clay matrix, which reduces the void ratio as well as the PI. Similar results were obtained by researchers incorporating $\mathrm{MD}$ and/or lime, RHA, or their mixtures $[3,17,21,22,54-56]$.

The modified soil matrix becomes more brittle as a result of flocculation, which also increases the coarse silt particles. Moreover, there occurs a continuous reduction in $G_{s}$ of RHA-treated soil due to which the PI is reduced while enhancing the "workability" of the additive-soil mixture [57]. On the contrary, for soil treated using MD, the plasticity reduction is attributed to the presence of higher $\mathrm{CaO}$ content $(49.5 \%)$ whose stabilization mechanism resembles that of lime treatment. The dissociation of lime into $\mathrm{Ca}^{2+}$ and $\mathrm{OH}^{-}$ions upon water addition leads to the ion exchange phenomenon. The $\mathrm{Na}^{+}$ions in the soil replace the $\mathrm{Ca}^{+2}$ ions to reduce the adsorption layer and eventually lower down the PI. The alkaline environment due to MD addition fosters the ion exchange phenomenon. That is to say, the increase in MD content would lead to higher ion exchanges [3].

4.2. Compaction Characteristics. Figures 6(a) and 6(b) illustrate the modified proctor compaction curves depicting variation between OMC and MDD for different MD/RHA content. The OMC decreased from $19 \%$ to $17 \%$ for MDblended soil, whereas it sharply increased from $19 \%$ to $25 \%$ for the RHA-treated soil. In addition, with MD treatment, the MDD slightly decreased to $1.70 \mathrm{~g} / \mathrm{cm}^{3}$ with increasing MD dosage, whereas, for the RHA-blended soil, MDD dropped significantly to $1.52 \mathrm{~g} / \mathrm{cm}^{3}$.

The increasing rate of OMC with varying RHA content is higher than that of lime and cement, while the MD-treated soil shows a different pattern in comparison with the rest of the additives. Similarly, the decrease in MDD is significant for $1 \%$ to $9 \%$ addition of both lime and cement than $2 \%$ to $12 \%$ blending with MD and RHA separately, with MD marking the least reduction of all. However, reference [37] concluded that MDD of medium plasticity clay is expected to increase with the addition of fly ash, MD, and "waste sand"; the results obtained in the present study are somewhat deviating because of two main aspects. Firstly, for the RHA-clay blends, the compaction curves move diagonally downward to the right with an increase in RHA content, which leads to a decrease in MDD and an increase in the OMC. The expansive soil particles are denser and replaced by light-weight RHA particles upon stabilization which decreases the weight of the proctor molds containing the compacted specimens of RHA-clay blends. Secondly, due to chemical reactions taking place, the density of MD or RHAtreated clays is decreased. Note that the decrease of OMC with increasing MD content is attributed to the fact that less amount of water would be required at a particular MDD at higher MD content. On the other hand, the rise in OMC for RHA-blended mixtures is attributed to the water absorption capability of RHA and an increase in SSA of the modified RHA blend. As a result, the water voids in the RHA-treated mixtures are increased, particularly at RHA contents beyond 


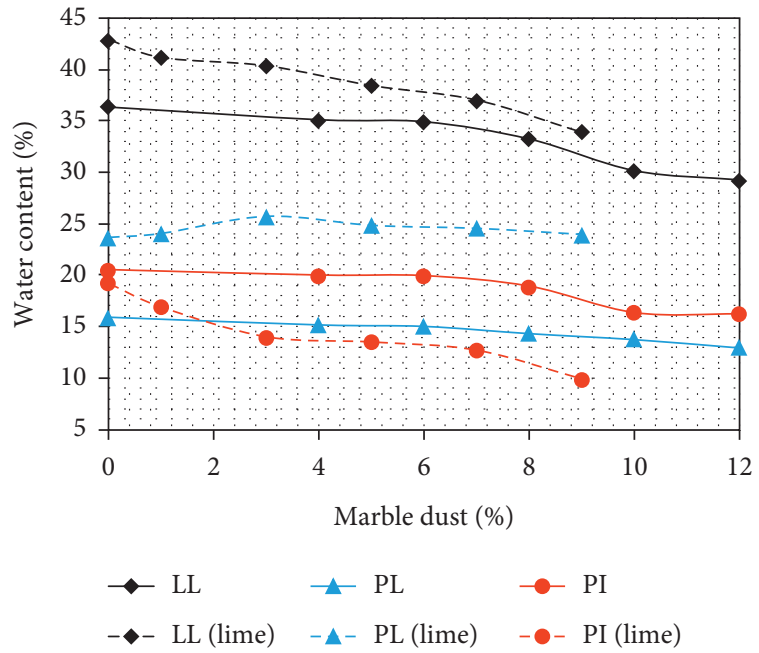

(a)

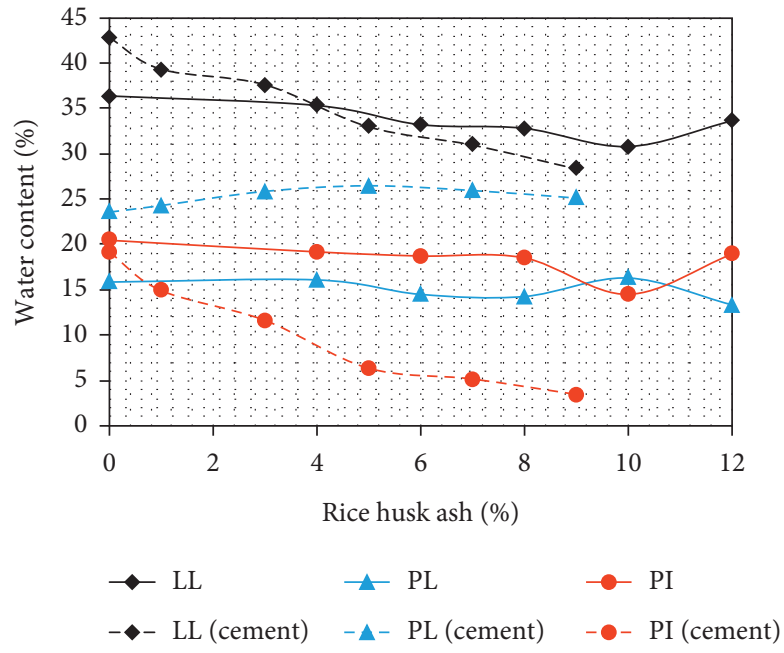

(b)

Figure 5: (a, b) Consistency limits with marble dust/rice husk ash. Note: Data of lime and cement in "a" and "b", is taken from Sharma et al. [18] for purpose of comparison.

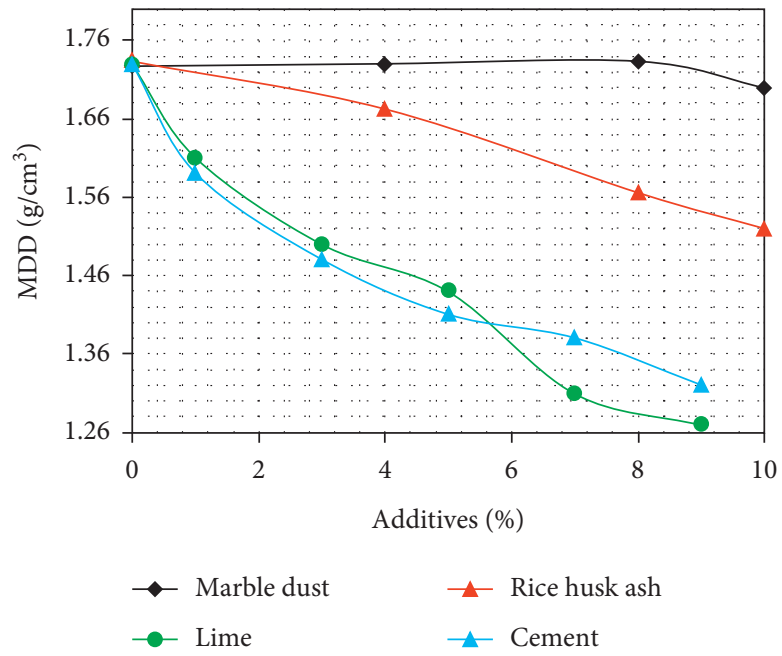

(a)

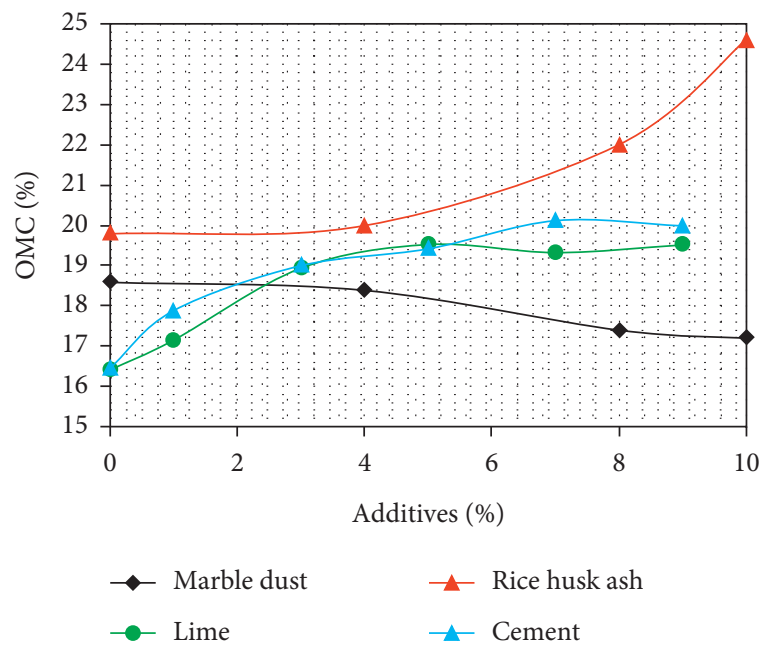

(b)

Figure 6: (a, b) Compaction characteristics with marble dust/rice husk ash. Note: Data of lime and cement in "a" and "b" is taken from Sharma et al. [18] for purpose of comparison.

$10 \%$, which increases the OMC. Moreover, the cation exchange also helps to increase the OMC. The replacement of soil particles by RHA granules would reduce the overall weight of the mixture, which are often preferable in a variety of Earth retaining structures, such as retaining walls [58]. These observations agree well with the findings of previous researchers [20, 21, 59-62].

4.3. Unconfined Compression Strength. The variation of compressive stress with varying $\mathrm{MD}$ content and RHA content is shown in Figures 7(a) and 7(b). At a particular stabilizer dosage, the UCS at 112 days was more than that at 3 days that is associated with the curing duration and increased rate of pozzolanic reaction.
Moreover, all the UCS values were enhanced for the MD/ RHA-clay blends. The rate of increase in UCS is the highest for MD/RHA-blended samples cured at 7 days. This is in line with past findings wherein the potential of sugarcane press mud material in the form of a secondary additive in conjunction with $\mathrm{CaO}$ for treating swelling soils was investigated [63]. An increase in UCS is reported by the addition of $8 \% \mathrm{MD}$ from $97 \mathrm{kPa}$ at 3 days to $471 \mathrm{kPa}$ at 112 days and for the $10 \%$ RHA-treated soil from $211 \mathrm{kPa}$ at 3 days to $665 \mathrm{kPa}$ at 112 days of curing.

The comparative study of MD and RHA stabilizers shows the overall UCS of RHA-treated soil is greater than that of MD-treated soil. It is due to the increased concentration of silicon, aluminum, and potassium ions in silica-rich RHA. The strength increase is associated with 


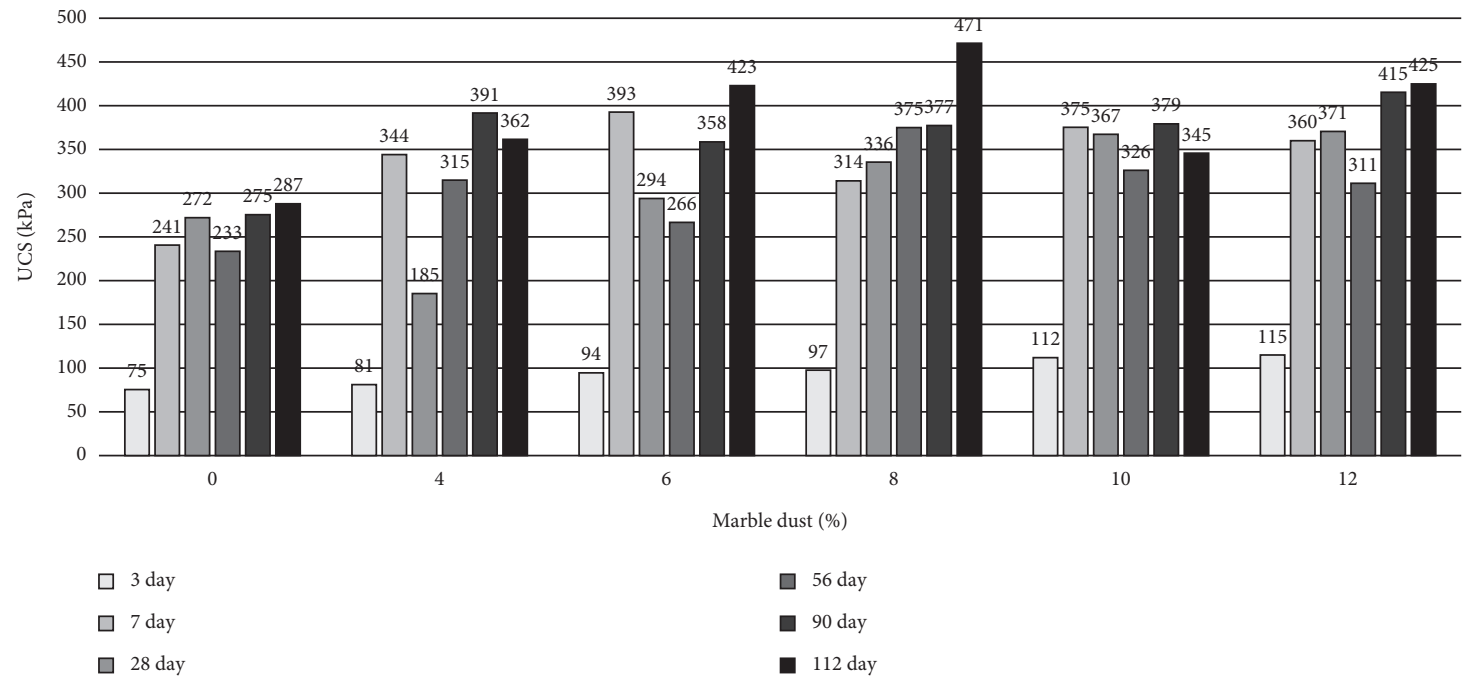

(a)

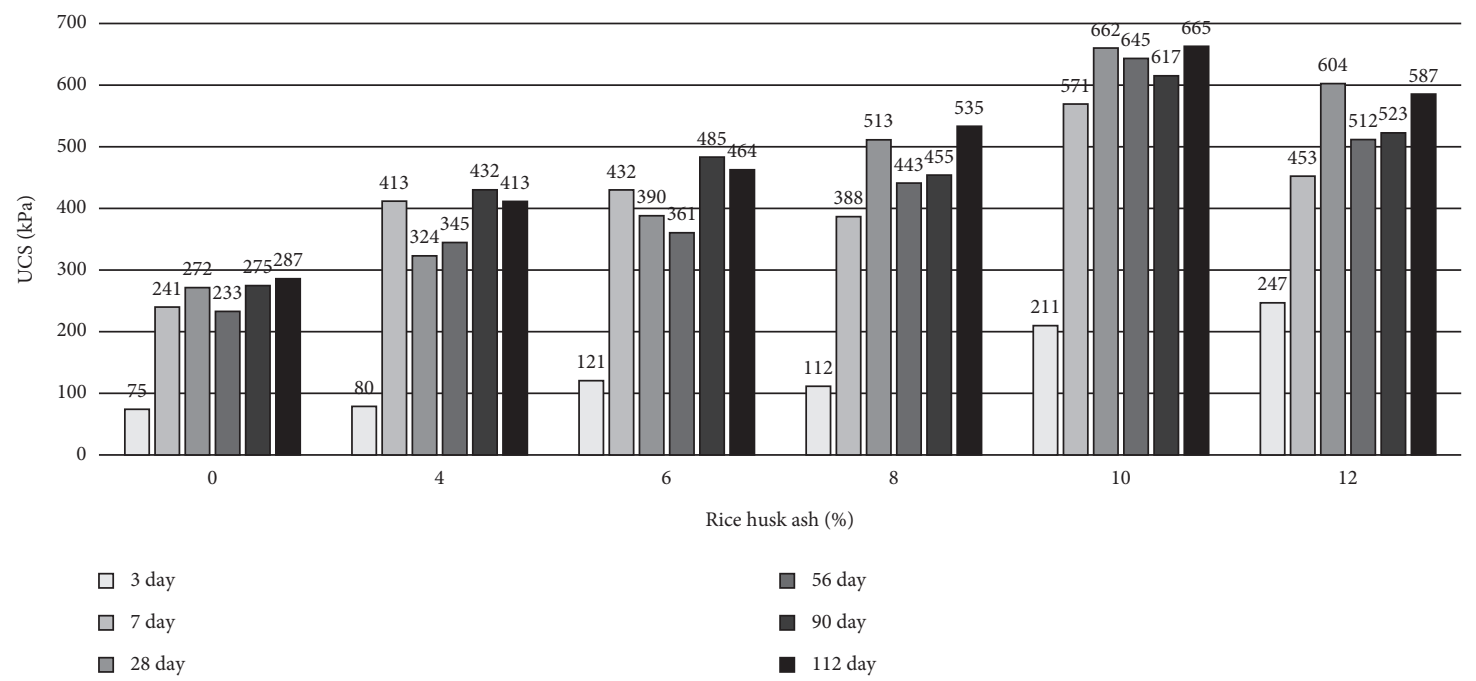

(b)

Figure 7: (a, b) Unconfined compression strength at 3, 7, 28, 56, 90, and 112 days with marble dust/rice husk ash.

the chemical reaction of additive and expansive clay particles occurring at a time spanning sample preparation and compression testing that leads to the formation of gelatinous compounds [64]. These compounds are formed during the progress of pozzolanic reactions. The differences in the OMC and maximum density of each blended specimen might also have contributed to strength enhancement. Maximum UCS was recorded for $10 \%$ stabilizer ratio at a curing period of 112 days. Similar results were obtained by [65] while studying the influence of recycled $\mathrm{MD}$ on the strength of concrete mortars. The UCS of stabilized soil decreased beyond the further addition of additives such that the reduction in RHAblended mixtures was comparatively more significant. It could be surmised that further addition of additives may inhibit the pozzolanic reaction. Additionally, it is also due to the decrease of MDD observed with increasing MD/ RHA content (Figures 6(a) and 6(b)). Thus, it can be inferred that the optimum amount of MD/RHA is $10 \%$ because the addition of $1-2 \%$ stabilizer has minimal effect on the compression strength of clay as it is not sufficient enough to start the pozzolanic reaction. However, the lower additive content affects the morphological and engineering behavior of the soil and does not significantly affect the strength parameters.

The strength of soil is increased as a result of shortterm (cation exchange and dissociation) and long-term (pozzolanic) reactions. The short-term reactions are responsible for an immediate reduction in the PI, and they increase the workability of the soil-additive mixtures. The pozzolanic reactions form $\mathrm{C}-\mathrm{S}-\mathrm{H}$ and $\mathrm{C}-\mathrm{A}-\mathrm{H}$ gels, exhibiting fiber-like structure and cementing properties which increase the cohesion among soil particles [63]. The various processes such as cation exchange reaction, flocculation and agglomeration, and long-term pozzolanic reactions govern the physiochemical phenomenon in lime stabilization of highly expansive soils [33]. The $\mathrm{Ca}^{+2}$ ions from the lime $(\mathrm{CaO})$ content in $\mathrm{MD}$ and the silica and 
alumina in the expansive soil undergo chemical reactions, that is, cation exchange, dissociation, pozzolanic process, and cementitious process.

4.3.1. Artificial Neural Network (ANN) Based Sensitivity Analyses for Compression Strength. Considering the interactive behavior of factors influencing the UCS of treated samples, an artificial neural network-based sensitivity analysis has been incorporated in order to simplify the complex response of treated soils in strength development. In order to achieve this, four parameters were selected as the dosage of agents (\%): plasticity index, optimum moisture content, and maximum dry density. The ANN model shown in Figure 8 consists of four variables with two hidden layers and UCS as the response variable. As UCS is considered to be one of the most vital factors in the process of soft soil stabilization, the relationship among the four independent variables, that is, MDD, OMC, PI, and Dosage, has been analyzed to ascertain the order and magnitude of influence of these variables on UCS. K-folded mechanisms have been implemented in this model by dividing the data set into five fractions, including a model on four fractions for training and on the fifth section for validation. The strength of the developed model was tested using acceptable root-meansquare error (RMSE) to determine the accuracy of the forecast of the system, and 0.99 coefficient of determination was achieved in the modeling.

The results of ANN-based sensitivity analyses, including variable order and magnitude of influence and variable impact profiler, are shown in Figures 9 and 10. Variable order and magnitude of influence on the final strength can be categorized in main and total effect as seen in Figures 9(a) and 10(a). The impact of the main effect of the response variable, namely, UCS $(y)$ among predicting variables MDD, OMC, PI, and Dosage $\left(X_{i t \mathrm{j} j}\right)$, on the predicted UCS can be described by $\operatorname{Var}\left(E\left(y \mid x_{j}\right)\right)$ [66]. The expectation is taken with respect to the conditional distribution of $x_{1}, x_{2}, \ldots, x_{n}$ given $x_{j}$, and the variance is taken over the distribution of $x_{j}$. In other words, $\operatorname{Var}\left(E\left(y \mid x_{i}\right)\right)$ measures the variation, over the distribution of $x_{i}$, in the mean of $y$ when $x_{i}$ is fixed. It is to say that the effecting indices utilized are main and total effect. The main effect is the ratio of $\operatorname{Var}\left(E\left(y \mid x_{i}\right)\right) / \operatorname{Var}(y)$, which gives a measure of the sensitivity of $y$ to the factor $x_{i}$, which reflects the relative contribution of that factor alone, not in combination with other factors, while the total effect represents the total contribution to the variance of $y=f\left(x_{1}\right.$, $x_{2}, \ldots, x_{j}$ ) from all terms that involve $x_{j}$, which reflects the relative contribution of that factor both alone and in combination with other factors [67].

With the total effect value, it is possible to represent the effects of single variables, pairs of variables, and so on. The total effect importance index for MDD, OMC, PI, and Dosage is an estimate of obtained UCS as follows:

$$
\text { total effect }=\frac{\operatorname{Var}\left(E\left(y \mid x_{i}\right)\right)+\operatorname{Var}\left(E\left(y \mid x_{1}, \ldots, x_{j}\right)\right.}{\operatorname{Var}(y)},
$$

where $E(y)$ is the expected value of UCS and $\operatorname{Var}(y)$ is the variance of UCS with respect to the joint distribution of MDD, OMC, PI, and Dosage. Moreover, profiling is an approach for visualizing the final response by seeing what would happen if a change occurs in one or two factors at a time and finding the most important factors to optimize the desired responses. In Figures 9(b) and 10(b), the vertical red lines correspond to the current value of each factor shown in red below the horizontal axis. The red value on the vertical axis is the predicted response based on the current values of the factors. The goal is to find the optimal combination of the four factors in the development of a certain UCS. With the aid of an impact profiler, it is possible to judge which factor or a pair of factors can optimize the desired UCS. Consequently, as can be seen in Figure 9(a) for treated soils with RHA, the PI value has the most effect on other variables regardless of incorporated dosage as can also be seen in Figure 6(b), followed by maximum dry density, and the role of incorporated dosage is not that significant which is in line with previous experimental findings comparing the consistency of treated samples. While this effect remains consistent over time, at 112 days of curing, as it is evident in Figure 9(a), the primary PI contributes even more to the UCS in contrast to 7-day treated samples reaching $549 \mathrm{kPa}$ from $435 \mathrm{kPa}$. These results show that RHA-treated samples are dependent on the developed PI during soil preparation, followed by the MDD of the reconstituted soil sample.

The behavior of MD-treated samples is prevalent in the soil stabilization field and in terms of the effect of dosage on the final strength. Although RHA-treated samples showed sensitivity towards the primary PI, they also react to the variation of incorporated dosage. But for MD-treated samples, the effect of change in dosage on the final strength is more noticeable. As it can be seen in Figure 10(b), treated samples with $4 \% \mathrm{MD}$ after 112 days of curing have reached a similar and not the exact UCS of treated samples with $6 \%$ $\mathrm{MD}$, meaning that the dosage has the governing effect on the final strength.

However, the consistency of treated samples does not depend on a sole factor as for 7-day cured samples, optimum moisture content has the second most effect on developed strength, while over a curing period and up to 112 days, the role of OMC diminishes and replaces by maximum dry density.

These observations again accentuate the fact that, besides parameters like Dosage or PI, which are more agent dependent, the relative density of stabilized samples prepared with the maximum dry density is generalized and remains consistent in contribution to the overall strength of any stabilized soil. With this remark at hand, it is now possible to ascertain the importance of MDD in soil stabilization from RHA-treated samples. As it is evident from Figure 9(b), and while it is already established that PI has the most influence on strength development, there should be the second most important factor, namely, MDD that contributes to the strength development over the curing period, while PI is set to 18 . 


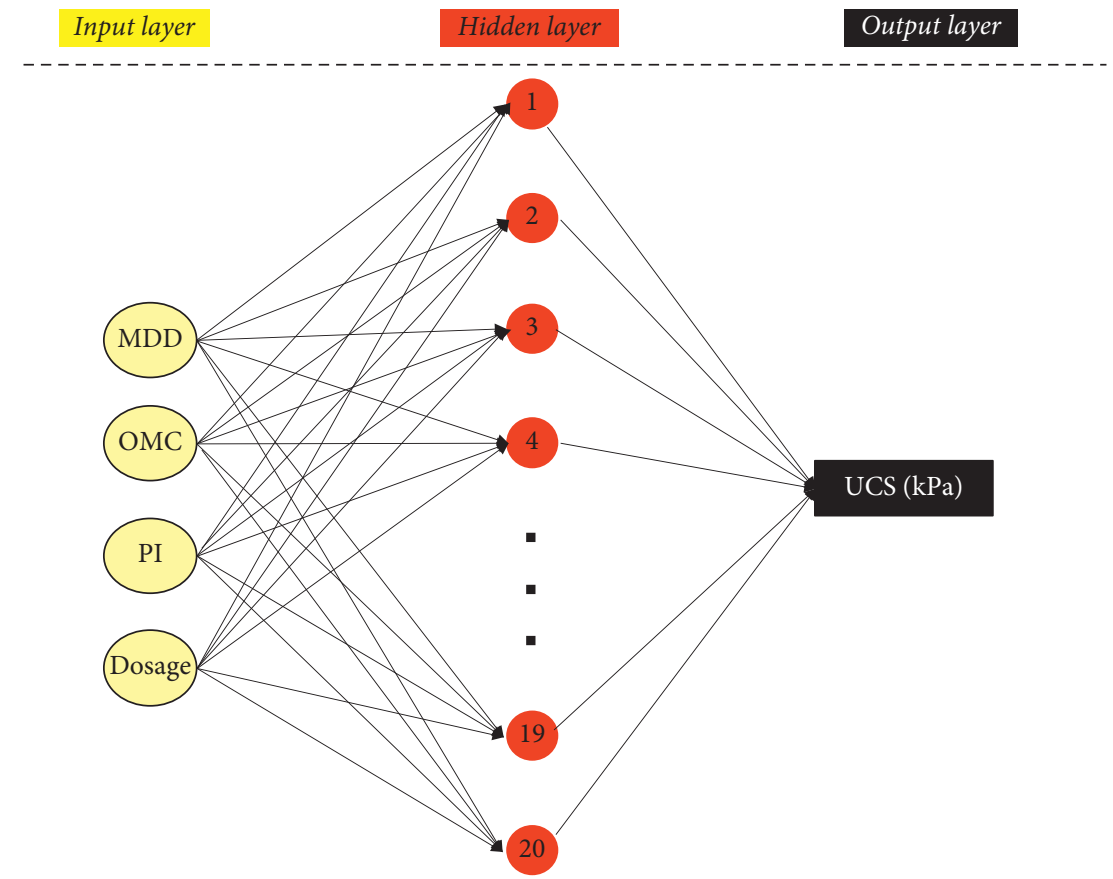

Figure 8: Artificial neural network (ANN) model configuration.

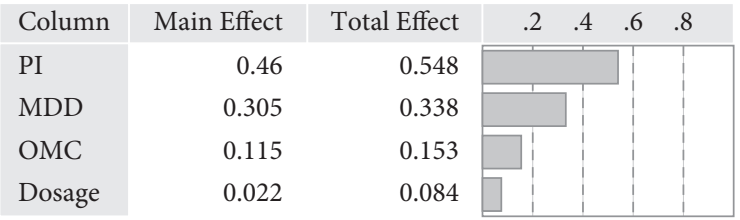

7 days RHA treated

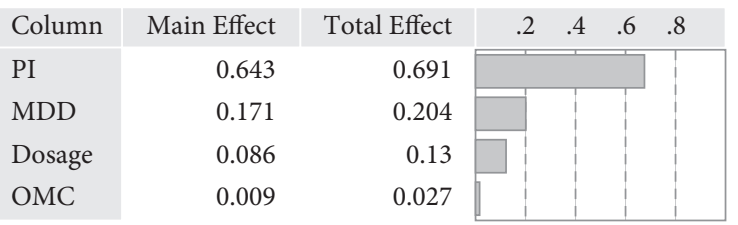

112days RHA treated

(a)

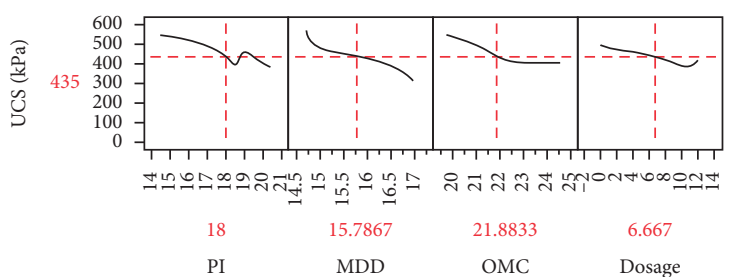

7 days RHA treated

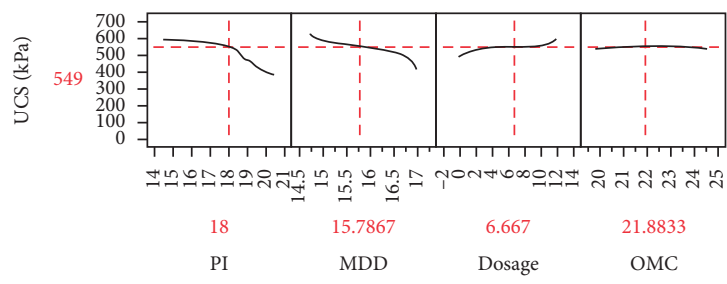

(b)

FIGURE 9: ANN-based sensitivity analyses: (a) variable order and magnitude of influence and (b) variable impact profiler for RHA-treated samples.

\subsection{Determination of Consolidation Characteristics}

4.4.1. Coefficient of Volume Change $\left(m_{v}\right)$. Figure 11(a) shows the relation between $m_{v}$ and preconsolidation pressure, $P_{c}$. It can be seen that irrespective of stabilizer type, $m_{v}$ initially increased from $0.00145 \mathrm{kPa}^{-1}$ to $0.0018 \mathrm{kPa}^{-1}$ and $0.00145 \mathrm{kPa}^{-1}$ to $0.0021 \mathrm{kPa}^{-1}$ for $\mathrm{MD}$-treated soils and RHA-treated clays, respectively, up to $6 \%$ dosage, whereas it decreased with further additives. The lower rate of volume change at low preconsolidation pressure is attributed to high void spaces at the beginning, which was later reduced by the increase in pressure, thus increasing the $m_{v}$. Beyond the peak value, a decreasing trend in $m_{v}$ is recorded for MD-treated and RHA-treated soil samples as the preconsolidation pressure increases, reaching $0.00132 \mathrm{kPa}^{-1}$ for $12 \%$ addition of $\mathrm{MD}$ and $0.0015 \mathrm{kPa}^{-1}$ for RHA. The reduction in the compressibility of the blended samples is because of the pore water salinity effects. The RHA-treated soil might have a higher diffused double layer (DDL) thickness which is responsible for the relatively higher $m_{v}$ values as compared with the soil-MD samples. It is because the DDL thickness is more for the case of pure water, and the specimen undergoes 


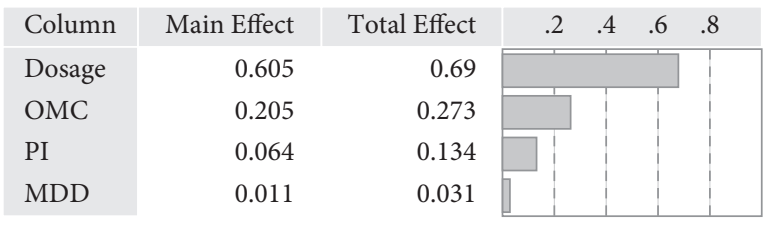

7 days MD treated

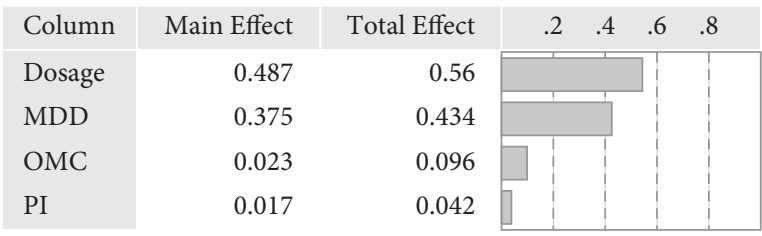

112 days MD treated

(a)
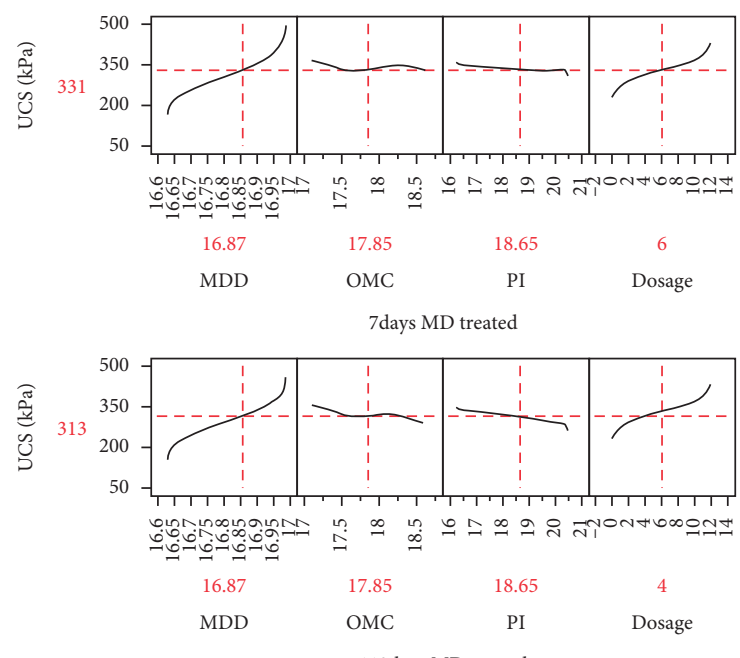

(b)

FIGURE 10: ANN-based sensitivity analyses: (a) variable order and magnitude of influence and (b) variable impact profiler for MD-treated samples.

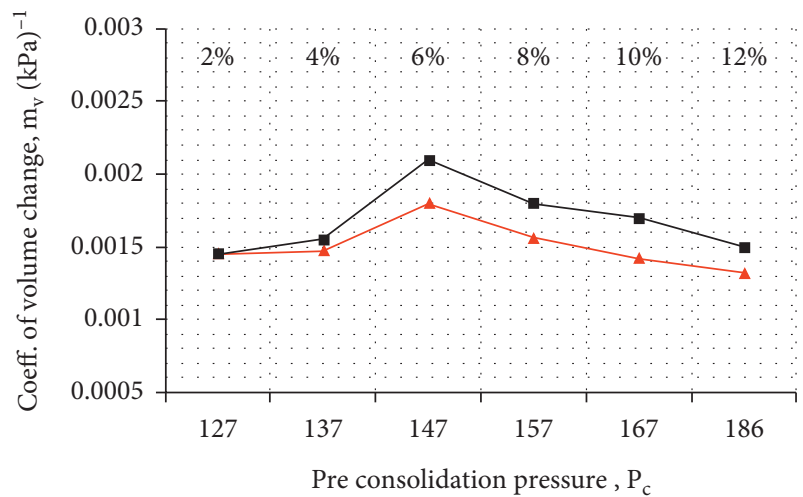

$\triangle$ Marble dust

Rice husk ash

(a)

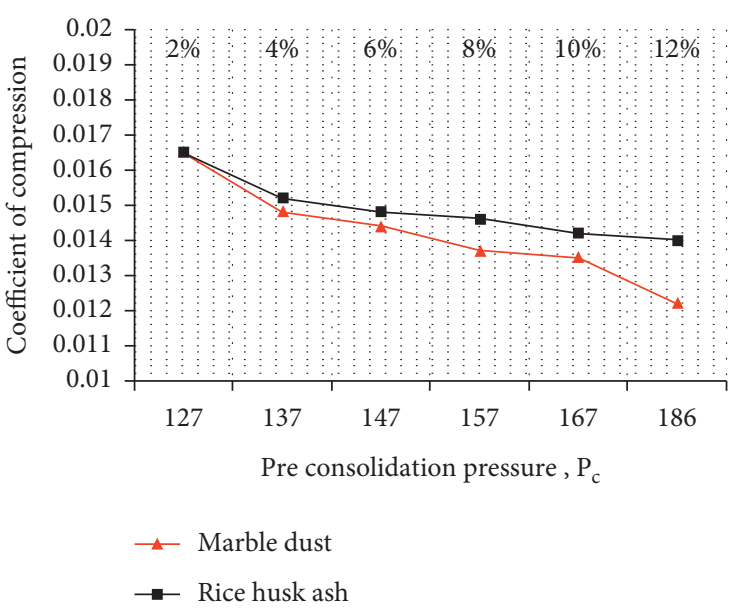

(c)

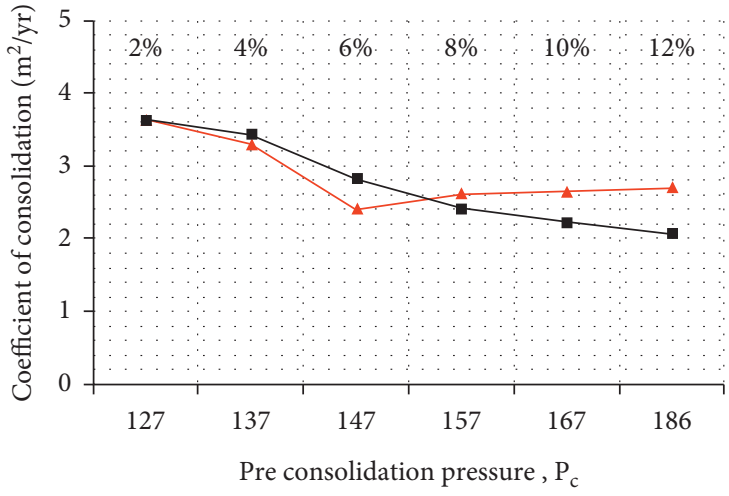

$\rightarrow$ Marble dust

$\rightarrow-$ Rice husk ash

(b)

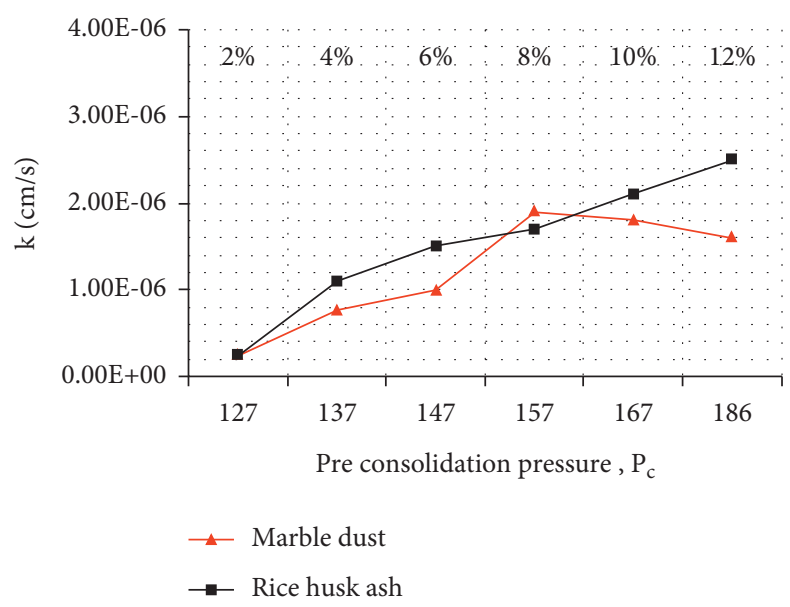

(d)

Figure 11: (a) The coefficient of volume change $m_{v}$. (b) The coefficient of consolidation $c_{v}$. (c) The coefficient compression $C_{c}$. (d) The coefficient of hydraulic conductivity $k$ versus preconsolidation pressure for soil blended with marble dust/rice husk ash. 
a greater compression as a result of pressure that is applied, which leads to higher $m_{v}$. With the decrease in thickness of the DDL due to higher salt concentration, the compressibility and therefore $m_{v}$ of the treated specimens reduce.

4.4.2. Coefficient of Consolidation $\left(c_{v}\right)$. In this paper, $c_{v}$ was estimated with the help of Taylor's method using equation (1) which was also applied to calculate the coefficient of hydraulic conductivity $(k)$ using correlation reported by [12]. Figure $11(\mathrm{~b})$ indicates that $c_{v}$ values steadily dropped from $3.64 \mathrm{~m}^{2} / \mathrm{yr}$ to $2.07 \mathrm{~m}^{2} / \mathrm{yr}$ with increasing preconsolidation pressure for RHA-treated clay. As a result, the consolidation rate becomes slow at greater preconsolidation pressures because $c_{v}$ is directly related to the rate of consolidation.

The same decreasing pattern was also reported by [51] for bentonite and by [68] for smectite clays. On the other hand, for MD-blended soil, $c_{v}$ decreases from $3.64 \mathrm{~m}^{2} / \mathrm{yr}$ to $2.4 \mathrm{~m}^{2} / \mathrm{yr}$ up to $6 \%$ additive, and then it increases from $2.4 \mathrm{~m}^{2} / \mathrm{yr}$ to $2.7 \mathrm{~m}^{2} / \mathrm{yr}$ upon further addition of $\mathrm{MD}$. It is because the compressibility behavior of soil samples is governed by mechanical factors for impure clays and by the forces of attraction and repulsion for the pure clays. This increase in $c_{v}$ might have occurred by a decrease in the DDL thickness, which increases the repulsive forces between the clay plates. Subsequently, the consolidation is inhibited and $c_{v}$ also decreases. An increasing pattern of $c_{v}$ with consolidation pressure was also reported by [69].

4.4.3. Compression Index $\left(C_{c}\right)$. Figure 11(c) shows the variation of $C_{c}$ and the preconsolidation pressure. It is illustrated that $C_{c}$ dropped with the rise in the preconsolidation pressure and the addition of MD/RHA. As the additive percentage increases, the clay particles undergo flocculation, which reduces the internal void spaces in the blended soil mixture and restrain settlement from occurring. Due to this, $C_{c}$ reduces from 0.0165 to 0.122 (26\%) for MDtreated soil and from 0.0165 to 0.014 (15\%) for RHA-treated specimens with additives blending of $4 \%$ to $12 \%$, as depicted in Figure 11(c). This can be attributed to the subsequent reduction in the $\mathrm{LL}$ values of the stabilized mixtures; however, the trend of LL could significantly deviate depending on the type and dosage of additives, as reported in past researches [51]. In addition, a reduction in $C_{c}$ will lead to lesser consolidation settlement, and this drop could be due to dense structure formed with the expansive clay particles [50].

\subsubsection{Hydraulic Conductivity (k). Figure 11(d) indicates} the variation of permeability with MD and RHA additives. For MD stabilized soil, the hydraulic conductivity increases from $2.4 \times 10^{-6} \mathrm{~cm} / \mathrm{s}$ to a peak value of $1.9 \times 10^{-7} \mathrm{~cm} / \mathrm{s}$ on the addition of $8 \% \mathrm{MD}$. After that, the $k$ value steadily drops to $1.6 \times 10^{-7} \mathrm{~cm} / \mathrm{s}$ at $12 \%$ dosage of $\mathrm{MD}$, whereas the RHA-treated soil is observed to follow a continuously increasing trend reaching $2.5 \times 10^{-7} \mathrm{~cm} / \mathrm{s}$ on the addition of $12 \%$ RHA. The range of values resembles those reported by $[21,70]$ while investigating the effect of RHA on concrete and high plastic expansive soil, respectively. The coefficient of permeability of RHA stabilized soil is higher than that of MD-treated samples at almost all dosage levels. The comparative increase in permeability of RHA-treated soil is attributed to two mechanisms. The comparative effect on hydraulic conductivity by RHA treatment is significant in terms of incremental increase. Firstly, the reduction in MDD with RHA dosage, as shown in Figure 6(b), and the void spaces in the stabilized soil are increased, thus allowing permeability to increase. Secondly, the decrease in the DDL thickness leads to greater repulsive forces between the clay plates of expansive soil, which will inhibit the consolidation process, thereby decreasing $c_{v}$, which finally increases the $k$ value. However, the permeability decreases at higher MD dosage, which may be due to the addition of stabilizer material densifying the soil-additives mixture, which in turn lowers both the $k$ and $c_{v}$ values.

\subsection{Mineralogical and Textural Characterization.} Microstructural analysis helps in understanding the physicochemical changes, morphology, and fabric of samples.

4.5.1. XRD Analysis. X-ray diffractograph of the specimens was conducted to investigate the hydration products on the basis of their crystallographic nature and to deduce the qualitative intensity comparison of the resulting products at different dosage levels. In order to understand the mineralogical changes in the soil treated with stabilizers, the XRD images of natural untreated expansive soil and stabilizer materials (12\% MD and 10\% RHA) after curing for 7, 28, 56, and 112 days are given in Figure 12. Various phases in the figure are identified using the X-ray diffractogram, which were produced between 15 and 70 2-theta value, by employing an X-ray polycrystal diffractometer at a scan speed of $0.62 \theta \mathrm{min}^{-1}$. It is seen that, at higher curing periods, new peaks corresponding to cementing gels, that is, $\mathrm{C}-\mathrm{S}-\mathrm{H}$ and $\mathrm{C}-\mathrm{A}-\mathrm{H}$, were formed. This can be attributed to the pozzolanic reactions taking place. These results are in good agreement with studies performed in the past $[18,71]$. The C-S-H gel formation is relatively slower in comparison with $\mathrm{C}-\mathrm{A}-\mathrm{H}$ gels which is associated with slower reactivity of silica atoms as compared with the aluminum cations.

4.5.2. SEM Analysis. The SEM images of untreated expansive soil, $12 \% \mathrm{MD}$, and $10 \% \mathrm{BA}$-treated soil after moist curing of $7,28,56$, and 112 days, magnified at $5 \mu \mathrm{m}$ and $10 \mu \mathrm{m}$, are shown in Figures13 and 14 .

The particles in the untreated expansive soil are bulky and less spherical, while their surfaces seem to be nonshiny, containing traces of dust within the matrix at both magnification levels. The ES-UT exhibited large pores and thin plate-like particles that are flat and smooth. ES-12M and ES$10 \mathrm{R}$ were chosen due to the pronounced changes obtained in the engineering and microstructural behavior of the treated expansive soil (Figures 13 and 14, respectively). The 


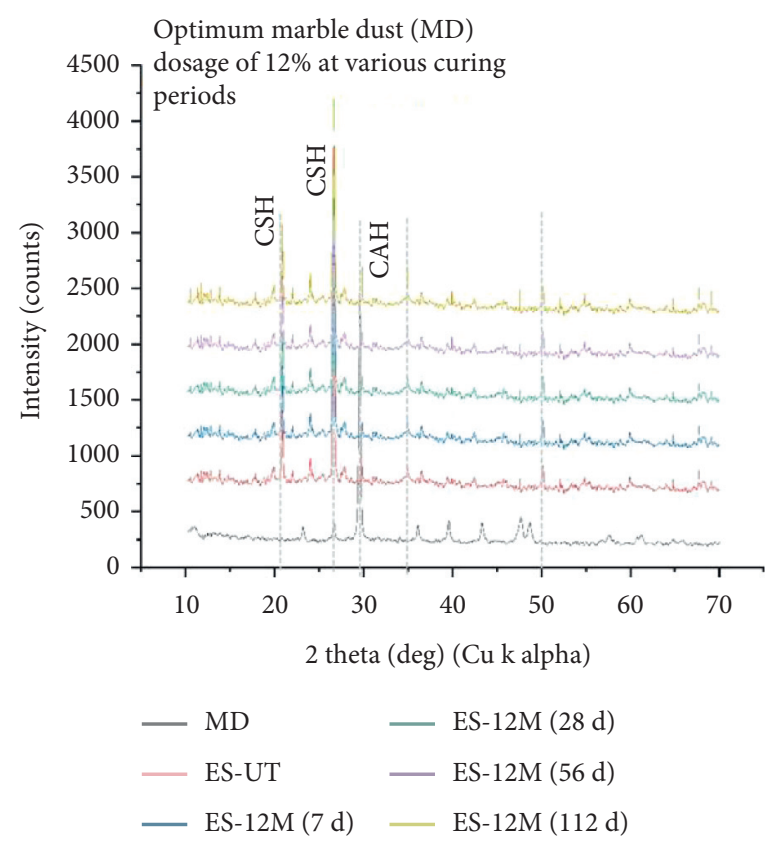

(a)

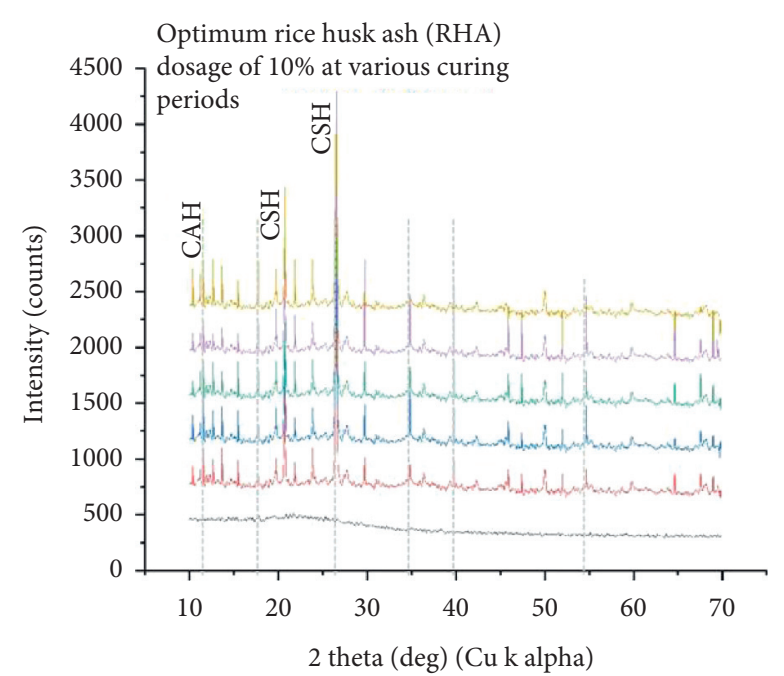

$\begin{array}{ll}- \text { RHA } & - \text { ES-10R }(28 \mathrm{~d}) \\ - \text { ES-UT } & - \text { ES-10R }(56 \mathrm{~d}) \\ - \text { ES-10R }(7 \mathrm{~d}) & - \text { ES-10R }(112 \mathrm{~d})\end{array}$

(b)

FIGURE 12: XRD analysis of stabilizer material, untreated expansive soil, and treated soil samples cured at 7, 28, 56, and 112 days for (a) $12 \%$ $\mathrm{MD}$ and (b) 10\% RHA dosage.

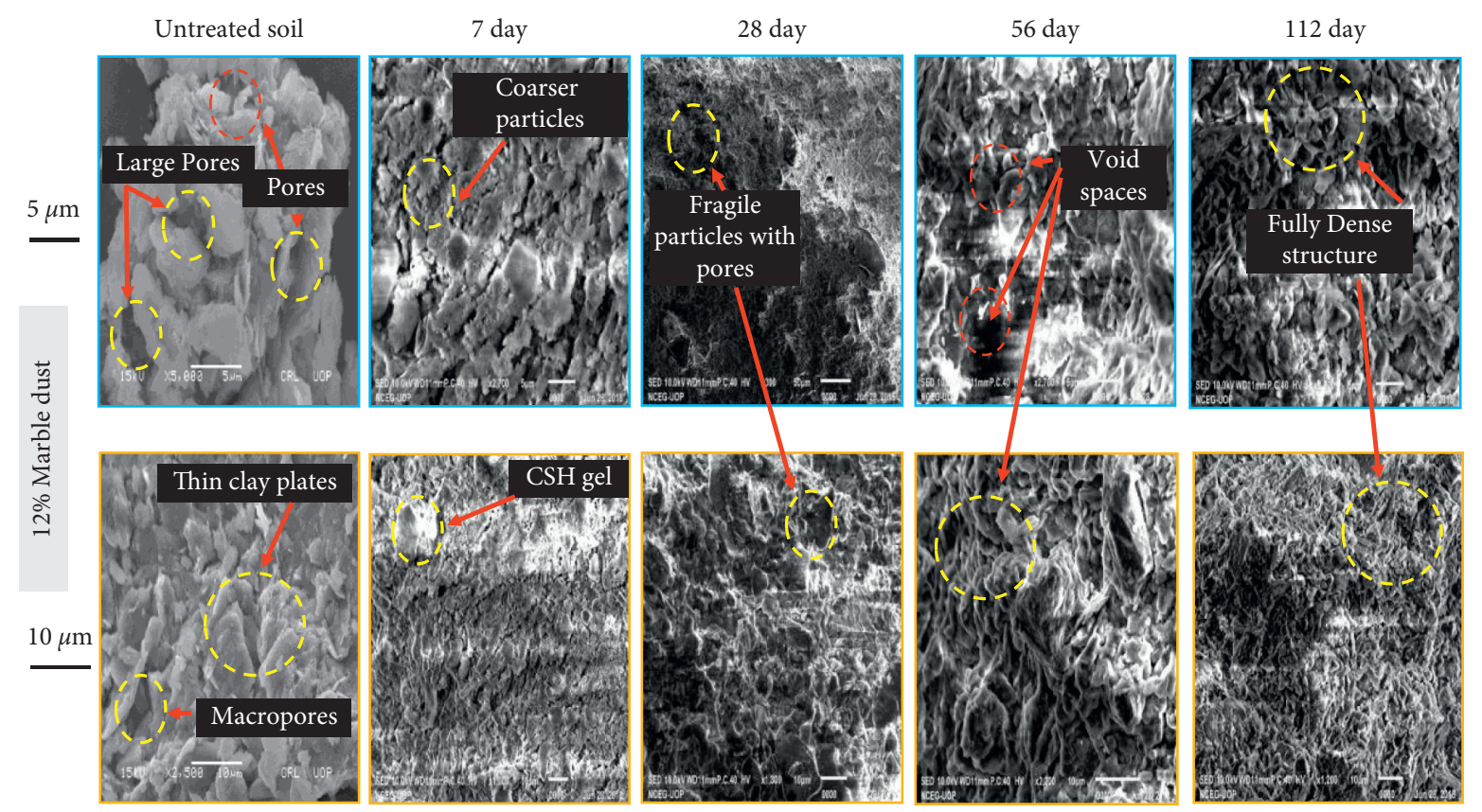

FIGURE 13: SEM micrographs of untreated expansive soil and 12\% MD-blended soil samples cured at 7, 28, 56, and 112 days.

formation of coarser and angular particles along with a dense network of fibrous C-S-H gel has taken place after 7 days of curing as shown in both MD- and RHA-treated soils. As a result, the interparticle attractions are increased, which decrease the plasticity and ultimately increase compression strength (see Figures 5 and 7, respectively). It also depicts the presence of very small-sized particles and some fine microfissures within the soil matrix. These results are consistent with observations reported by previous researchers $[18,72,73]$. The brighter cementing gel formed after 7 days of curing represents the C-S-H and C-A-H gels, which enhances the soil strength. These results are in good agreement with the microstructure obtained by [74]. After 28- and 56-day curing period, the fragile particles with pores and macropores are seen in case of MD-treated soil, signifying the irregular surface morphology. In addition, the 


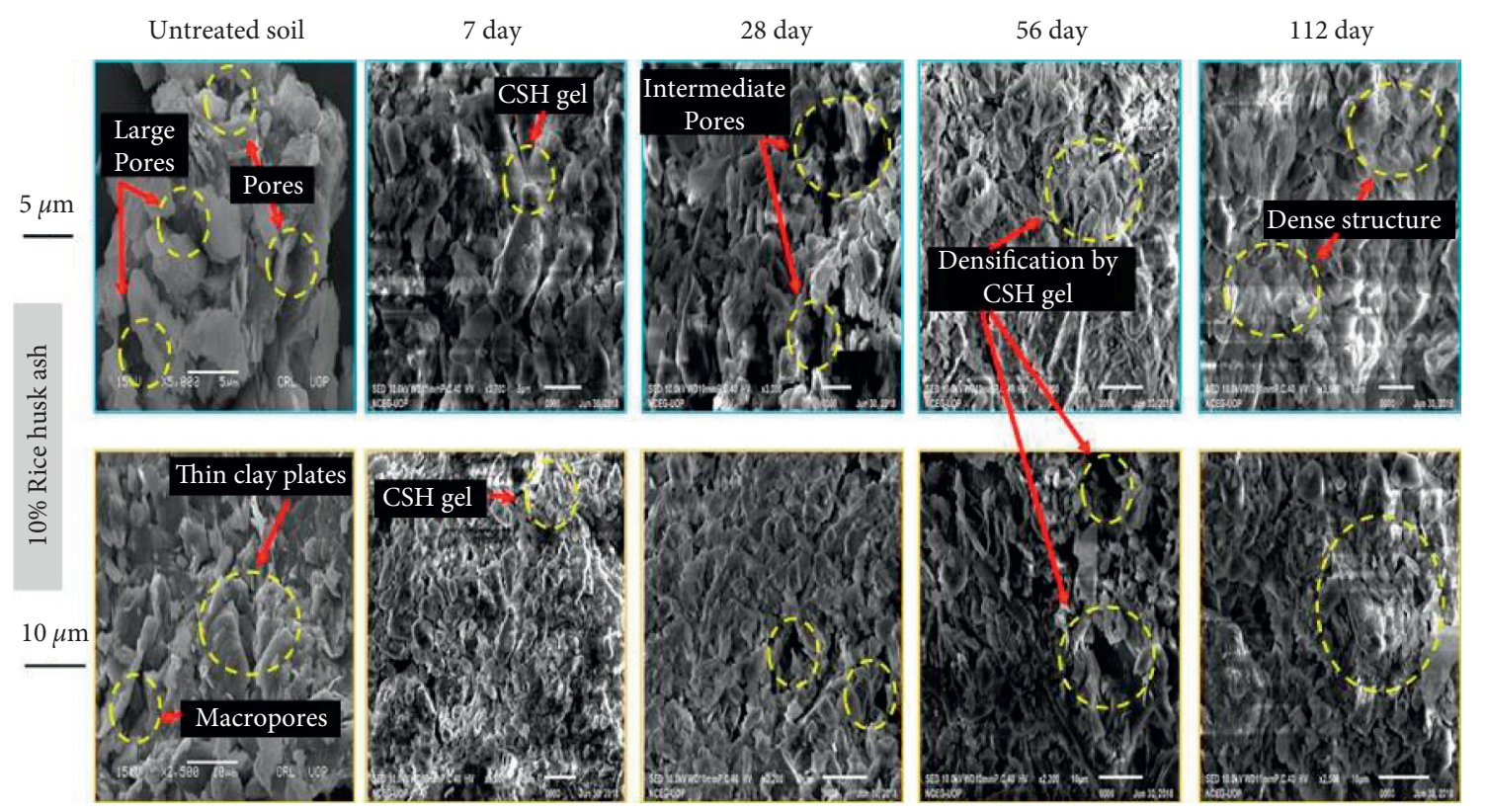

FIGURE 14: SEM micrographs of untreated expansive soil and 10\% RHA-blended soil samples cured at 7, 28, 56, and 112 days.

link between the clay particles is weakened, which is responsible for the dispersion of soil particles having loose aggregations (amorphous structure) with haphazard arrangement of the particles. However, the formation of C-S$\mathrm{H}$ in RHA-treated clays at 56 days of curing added to the overall compression strength, unlike MD-treated clays at the same dosage level. After 112 days of curing, the micrographs of MD/RHA-clay mixtures are in good agreement with the mechanism described for 7 days of curing regarding the formation of cementitious gels. A similar increase in strength after 112 days of curing period has been reported by [37]. The microfissures are significantly minimized as rough and gritty surface texture could be observed in the SEM images. It is associated with ion exchange and flocs formation, which takes place in alkaline environment and is responsible for decreasing the water holding capacity of clay particles. These were characterized by the presence of dense cementitious compounds. Moreover, the higher flocculation depicted in Figure 13 is caused by the increase in the $\mathrm{Ca}^{+2}$ ions in MD-blended mixtures [50]. As a result, there is an overall improvement of strength $[75,76]$ in case of blending soil with $12 \% \mathrm{MD}$ and $10 \% \mathrm{RHA}$, which is also corroborated by the Atterberg limits, hydraulic conductivity, and UCS tests (see Figures 5 to 7 ).

\section{Conclusions}

The current study deals with the incorporation of additives such as marble dust/rice husk ash to modify the properties of an expansive soil. The findings of this investigation can be applied particularly in the construction of pavements resting on expansive soil. Based on the above-mentioned results and discussion, the following conclusions can be drawn:

(1) The addition of MD/RHA significantly affected the geotechnical and morphological characteristics of expansive soil. Moreover, the duration of curing and dosage level of additives largely affected the engineering properties of the soil.

(2) The optimum moisture content (OMC) increased for RHA-treated soil, whereas it decreased for MDtreated soil, on the addition of up to $12 \%$ additive dosage. The exponential rise in OMC of RHAblended soil is attributed to the water absorption capability of RHA and the increase in SSA of the modified blends. The reduction in OMC with MD dosage is due to less amount water is required at a particular MDD, particularly at higher MD content. The maximum dry density (MDD) decreased with the addition of MD/RHA. However, having ANNbased sensitivity analysis at hand, MDD remains as the top influencer of treated soil regardless of incorporated dosage.

(3) The unconfined compression strength (UCS) tests indicate that the use of $12 \% \mathrm{MD}$ and $10 \%$ RHA effectively improved the compression strength. The curing had an obvious effect on the UCS, and the blending of $12 \% \mathrm{MD}$ and $10 \% \mathrm{RHA}$ led to the maximum average strength after 112 days of curing. The soil-RHA exhibited greater development of UCS values in both experimental and ANN-based analysis than the soil-MD mixtures over the curing periods.

(4) In the oedometer tests, $m_{v}$ initially increased up to $6 \%$ dosage and then dropped with further increase in the preconsolidation pressure. It infers that RHAtreated soil might have a higher diffused double layer (DDL) thickness that is responsible for higher $m_{v}$ compared with the MD-blended samples. For RHAtreated clay, the $c_{v}$ values steadily dropped with increasing preconsolidation pressure, which represents that the consolidation rate was steady at greater 
preconsolidation pressures. For MD-treated soil, $c_{v}$ decreased up to $6 \%$ additive and then increased afterwards.

(5) The compression index dropped with an increase in the preconsolidation pressure and addition of MD/RHA. The coefficient of permeability $(k)$ of RHA stabilized soil was higher than that of MD-treated samples for almost all dosage levels. The comparative increase in permeability of RHA-treated soil is attributed to the decrease in MDD with the addition of RHA.

(6) The mineralogical and morphological behavior of the expansive soil was significantly affected by the MD/ RHA replacement. According to the XRD analysis, the formation of montmorillonite in the untreated expansive soil showed the presence of hydrophilic smectites in the native soil, while the SEM micrographs indicate the microstructural changes, carbonation, and formation of gel-like and fibrous compounds, that is, C-S-H and C-A-H in the soiladditive matrix.

\section{Data Availability}

No data were used to support this study.

\section{Conflicts of Interest}

The authors declare that they have no conflicts of interest.

\section{Acknowledgments}

This research was supported by Nazarbayev University Faculty Development Competitive Research Grant no. 021220FD0651. Also, the authors would like to thank COMSATS University, Islamabad, Abbottabad Campus, Pakistan, for providing the laboratory facility. Efforts by Engr. Huzefa and Engr. Hussain (the great footballers of COMSATS University) in performing lab tests are highly acknowledged.

\section{References}

[1] H. Elbadry, "Simplified reliable prediction method for determining the volume change of expansive soils based on simply physical tests," HBRC Journal, vol. 13, no. 3, pp. 353-360, 2017.

[2] J. Ma, Y. Su, Y. Liu, and X. Tao, "Strength and microfabric of expansive soil improved with rice husk ash and lime," Advances in Civil Engineering, vol. 2020, Article ID 9646205, 8 pages, 2020.

[3] Y. Liu, Y. Su, A. Namdar, G. Zhou, Y. She, and Q. Yang, "Utilization of cementitious material from residual rice husk ash and lime in stabilization of expansive soil," Advances in Civil Engineering, vol. 2019, Article ID 5205276, 17 pages, 2019.

[4] K. C. Onyelowe, F. E. Jalal, M. E. Onyia, I. C. Onuoha, and G. U. Alaneme, "Application of gene expression programming to evaluate strength characteristics of hydrated-limeactivated rice husk ash-treated expansive soil," Applied Computational Intelligence and Soft Computing, vol. 2021, Article ID 6686347, 17 pages, 2021.
[5] N. Ijaz, F. Dai, and Z. u. Rehman, "Paper and wood industry waste as a sustainable solution for environmental vulnerabilities of expansive soil: a novel approach," Journal of Environmental Management, vol. 262, Article ID 110285, 2020.

[6] M. Li, Y. Wei, Y. Liu, and J. Jin, "A framework for interpreting lateral swelling pressure in unsaturated expansive soils," Advances in Civil Engineering, vol. 2021, Article ID 6626835, 15 pages, 2021.

[7] I. C. Christopher and N. D. Chimobi, "Emerging trends in expansive soil stabilisation: a review," Journal of Rock Mechanics and Geotechnical Engineering, vol. 11, no. 2, 2019.

[8] F. E. Jalal, Y. Xu, B. Jamhiri, and S. A. Memon, "On the recent trends in expansive soil stabilization using calcium-based stabilizer materials (CSMs): a comprehensive review," Advances in Materials Science and Engineering, vol. 2020, Article ID 1510969, 23 pages, 2020.

[9] M. Aziz, M. Saleem, and M. Irfan, "Engineering behavior of expansive soils treated with rice husk ash," Geomechanics and Engineering, vol. 8, no. 2, pp. 173-186, 2015.

[10] A. Akbar and K. Farooq, "Expansive soils IN Pakistan-case histories," JOURNAL OF ENGINEERING AND APPLIED SCIENCES, vol. 21, no. 1, pp. 119-129, 2002.

[11] M. Mahedi, B. Cetin, and D. J. White, "Cement, lime, and fly ashes in stabilizing expansive soils: performance evaluation and comparison," Journal of Materials in Civil Engineering, vol. 32, no. 7, Article ID 04020177, 2020.

[12] A. Sridharan and Y. Gurtug, "Swelling behaviour of compacted fine-grained soils," Engineering Geology, vol. 72, no. 12, pp. 9-18, 2004.

[13] A. Seco, F. Ramírez, L. Miqueleiz, and B. García, "Stabilization of expansive soils for use in construction," Applied Clay Science, vol. 51, no. 3, pp. 348-352, 2011.

[14] W. J. Negawo, G. D. Emidio, A. Bezuijen, R. D. F. Verastegui, and B. François, "Lime-stabilisation of high plasticity swelling clay from Ethiopia," European Journal of Environmental and Civil Engineering, vol. 23, no. 4, pp. 504-514, 2019.

[15] K. Terzaghi, R. B. Peck, and G. Mesri, Soil Mechanics in Engineering Practice, John Wiley \& Sons, NJ, USA, 1996.

[16] M. A. A. Bared, I. Harahap, A. Marto, and S. V. A. N. K. Abad, "Mechanical behaviour of waste powdered tiles and Portland cement treated soft clay," Geomechanics and Engineering, vol. 19, no. 1, pp. 37-47, 2019.

[17] F. G. Bell, "Lime stabilization of clay minerals and soils," Engineering Geology, vol. 42, no. 4, pp. 223-237, 1996.

[18] L. K. Sharma, N. N. Sirdesai, K. M. Sharma, and T. N. Singh, "Experimental study to examine the independent roles of lime and cement on the stabilization of a mountain soil: a comparative study," Applied Clay Science, vol. 152, pp. 183-195, 2018.

[19] A. Puppala, H. Laureano, V. Chirayus, and M. Chisha, "Fiber and fly ash stabilization methods to treat soft expansive soils," in Proceedings of the Soft Ground Technology, pp. 136-145, Noordwijkerhout, Netherlands, May 2000.

[20] A. Kumar and D. Gupta, "Behavior of cement-stabilized fiberreinforced pond ash, rice husk ash-soil mixtures," Geotextiles and Geomembranes, vol. 44, no. 3, pp. 466-474, 2016.

[21] B. R. Phanikumar and T. V. Nagaraju, "Effect of fly ash and rice husk ash on index and engineering properties of expansive clays," Geotechnical \& Geological Engineering, vol. 36, no. 6, pp. 3425-3436, 2018.

[22] M. Alhassan, "Potentials of rice husk ash for soil stabilization," Assumption university journal of technology, vol. 11, no. 4, pp. 246-250, 2008. 
[23] Y. Liu, C. W. Chang, A. Namdar et al., "Stabilization of expansive soil using cementing material from rice husk ash and calcium carbide residue," Construction and Building Materials, vol. 221, pp. 1-11, 2019.

[24] L. A. D. O. Pereira, J. P. C. Gomes, and P. M. S. Santos, "The potential pozzolanic activity of glass and red-clay ceramic waste as cement mortars components," Construction and Building Materials, vol. 31, pp. 197-203, 2012.

[25] C. Medina, M. Frías, and M. I. D. R. Sánchez, "Microstructure and properties of recycled concretes using ceramic sanitary ware industry waste as coarse aggregate," Construction and Building Materials, vol. 31, pp. 112-118, 2012.

[26] A. F. Cabalar, D. I. Hassan, and M. D. Abdulnafaa, "Use of waste ceramic tiles for road pavement subgrade," Road Materials and Pavement Design, vol. 18, no. 4, pp. 882-896, 2017.

[27] A. Mostafa, M. S. Ouf, and M. Elgendy, "Stabilization of subgrade pavement layer using silica fume and nano silica," International Journal of Scientific Engineering and Research, vol. 7, no. 3, pp. 573-581, 2016.

[28] M. A. Pashabavandpouri and S. Jahangiri, "Effect of nano silica on swelling, compaction and strength properties of clayey soil stabilized with lime," J Appl Environ Biol Sci, vol. 5, no. 7S, pp. 538-548, 2015.

[29] A. Kampala and S. Horpibulsuk, "Engineering properties of silty clay stabilized with calcium carbide residue," Journal of Materials in Civil Engineering, vol. 25, no. 5, pp. 632-644, 2012.

[30] S. Lee, I. Chang, M. K. Chung, Y. Kim, and J. Kee, "Geotechnical shear behavior of xanthan gum biopolymer treated sand from direct shear testing," Geomechanics and Engineering, vol. 12, no. 5, pp. 831-847, 2017.

[31] S. Leela, J. Im, G. C. Cho, and I. Chang, "Laboratory triaxial test behavior of xanthan gum biopolymer-treated sands," Geomechanics and Engineering, vol. 17, no. 5, pp. 445-452, 2019.

[32] D. Hunter, "Lime-induced heave in sbearing clay soils," Journal of geotechnical engineering, vol. 114, no. 2, pp. 150$167,1988$.

[33] A. Behnood, "Soil and clay stabilization with calcium- and non-calcium-based additives: a state-of-the-art review of challenges, approaches and techniques," Transportation Geotechnics, vol. 17, pp. 14-32, 2018.

[34] B. J. S. Varaprasad, J. R. Jayaprakash, and J. R. Suryaprakash, "Exploratory study on argo-industrial wastes for improving geotechnical properties of expansive soil - as sustainable material," Materials Today: Proceedings, vol. 45, pp. 66656673, 2021.

[35] P. Parik and N. R. Patra, "Static and dynamic properties of expansive soil stabilised with industrial waste," in Proceedings of the Geo-Congress 2020: Foundations, Soil Improvement, and Erosion. 2020, Minneapolis, Minnesota, February 2020.

[36] M. M. S. Lopes, R. D. C. S. S. A. Alvarenga, L. G. Pedroti et al., "Influence of the incorporation of granite waste on the hiding power and abrasion resistance of soil pigment-based paints," Construction and Building Materials, vol. 205, pp. 463-474, 2019.

[37] S. Firat, J. M. Khatib, G. Yilmaz, and A. Comert, "Effect of curing time on selected properties of soil stabilized with fly ash, marble dust and waste sand for road sub-base materials," Waste Management \& Research, vol. 35, no. 7, pp. 747-756, 2017.

[38] J. M. Marangu, C. M. M’thiruaine, and M. Bediako, "Physicochemical properties of hydrated portland cement blended with rice husk ash," Journal of Chemistry, vol. 2020, Article ID 5304745, 10 pages, 2020.

[39] M. A. A. Bared, I. Harahap, A. Marto, and S. V. A. N. K. Abad, "Undrained shear strength and microstructural characterization of treated soft soil with recycled materials," Geomechanics and Engineering, vol. 18, no. 4, pp. 427-437, 2019.

[40] N. Zainuddin, N. Z. Y. Mohd, M. A. M. Al-Bared, A. Marto, I. S. H. Harahap, and A. S. A. Rashid, "Measuring the engineering properties of marine clay treated with disposed granite waste," Measurement, vol. 131, pp. 50-60, 2019.

[41] H. Şahan Arel, "Recyclability of waste marble in concrete production," Journal of Cleaner Production, vol. 131, pp. 179-188, 2016.

[42] D. K. Ashish, "Feasibility of waste marble powder in concrete as partial substitution of cement and sand amalgam for sustainable growth," Journal of Building Engineering, vol. 15, pp. 236-242, 2018.

[43] M. A. Mosaberpanah, "Utilizing rice husk ash as supplement to cementitious materials on performance of ultra high performance concrete-A review," Materials Today Sustainability, vol. 7-8, Article ID 100030, 2019.

[44] T. H. Le, D. T. T. Le, and N. V. Tung, "Synthesis of colloidal silicon quantum dot from rice husk ash," Journal of Chemistry, vol. 2021, Article ID 6689590, 9 pages, 2021.

[45] E. M. A. Basha, R. Hashim, and A. S. Muntohar, "Effect of the cementrice husk ash on the plasticity and compaction of soil," Electronic Journal of Geotechnical Engineering, vol. 8, no. 1, pp. 1-8, 2003.

[46] S. A. Memon, M. A. Shaikh, and H. Akbar, "Utilization of rice husk ash as viscosity modifying agent in self compacting concrete," Construction and Building Materials, vol. 25, no. 2, pp. 1044-1048, 2011.

[47] R. J. Gonawala, R. Kumar, and K. A. Chauhan, "Stabilization of expansive soil with corex slag and lime for road subgrade," in Proceedings of the International Congress and Exhibition" Sustainable Civil Infrastructures: Innovative Infrastructure Geotechnology, Springer, Cairo, Egypt, November 2018.

[48] T. M. Petry and D. N. Little, "Review of stabilization of clays and expansive soils in pavements and lightly loaded structures-history, practice, and future," Journal of Materials in Civil Engineering, vol. 14, no. 6, pp. 447-460, 2002.

[49] A. S. Ruiz, M. P. Sánchez, and M. Rozalen, "Waste marble dust: an interesting residue to produce cement," Construction and Building Materials, vol. 224, pp. 99-108, 2019.

[50] O. E. Oluwatuyi, O. O. Ojuri, and A. Khoshghalb, "Cementlime stabilization of crude oil contaminated kaolin clay," Journal of Rock Mechanics and Geotechnical Engineering, vol. 12, no. 1, 2020.

[51] J. Dutta and A. K. Mishra, "Consolidation behaviour of bentonites in the presence of salt solutions," Applied Clay Science, vol. 120, pp. 61-69, 2016.

[52] A. Sridharan and H. Nagaraj, "Coefficient of consolidation and its correlation with index properties of remolded soils," Geotechnical Testing Journal, vol. 27, no. 5, pp. 469-474, 2004.

[53] A. A. A. Rawas, A. W. Hago, and H. Al-Sarmi, "Effect of lime, cement and Sarooj (artificial pozzolan) on the swelling potential of an expansive soil from Oman," Building and Environment, vol. 40, no. 5, pp. 681-687, 2005.

[54] J. Jha and K. Gill, "Effect of rice husk ash on lime stabilization of soil," Journal of the Institution of Engineers (India), Part CV, Civil Engineering Division, vol. 87, pp. 33-39, 2006.

[55] P. Dahale, P. Nagarnaik, and A. Gajbhiye, "Effect OF flyash and lime ON stabilization OF expansive soil," $i$-Manager's Journal on Civil Engineering, vol. 6, no. 2, p. 8, 2016. 
[56] C. Gupta and R. K. Sharma, "Influence of marble dust, fly ash and beas sand on sub grade characteristics of expansive soil," Journal of Mechanical and Civil Engineering, vol. 2014, pp. 13-18, 2014.

[57] A. S. Muntohar and G. Hantoro, "Influence of rice husk ash and lime on engineering properties of a clayey subgrade," Electronic Journal of Geotechnical Engineering, vol. 5, pp. 1-9, 2000.

[58] D. Gupta and A. Kumar, "Performance evaluation of cementstabilized pond ash-rice husk ash-clay mixture as a highway construction material," Journal of Rock Mechanics and Geotechnical Engineering, vol. 9, no. 1, pp. 159-169, 2017.

[59] E. Ene and C. Okagbue, "Some basic geotechnical properties of expansive soil modified using pyroclastic dust," Engineering Geology, vol. 107, no. 1-2, pp. 61-65, 2009.

[60] S. G. Lu, F. F. Sun, and Y. T. Zong, "Effect of rice husk biochar and coal fly ash on some physical properties of expansive clayey soil (Vertisol)," Catena, vol. 114, pp. 37-44, 2014.

[61] F. G. Bell, Engineering Treatment of Soils, CRC Press, Florida USA, 2014.

[62] S. Kolias, V. K. Rigopoulou, and A. Karahalios, "Stabilisation of clayey soils with high calcium fly ash and cement," Cement and Concrete Composites, vol. 27, no. 2, pp. 301-313, 2005.

[63] J. James, "Sugarcane press mud modification of expansive soil stabilized at optimum lime content: strength, mineralogy and microstructural investigation," Journal of Rock Mechanics and Geotechnical Engineering, vol. 12, no. 2, pp. 395-402, 2020.

[64] C. M. Geiman, Stabilization Of Soft Clay Subgrades In Virginia $\hat{A}$ Phase I Laboratory Study, Virginia Tech, Virginia USA, 2005.

[65] L. G. Li, Z. H. Huang, Y. P. Tan, A. K. H. Kwan, and H. Y. Chen, "Recycling of marble dust as paste replacement for improving strength, microstructure and eco-friendliness of mortar," Journal of Cleaner Production, vol. 210, pp. 55-65, 2019.

[66] S. Im, "Sensitivity estimates for nonlinear mathematical models," Mathematical Modelling in Civil Engineering, vol. 1, no. 4, pp. 407-414, 1993.

[67] G. Derringer and R. Suich, "Simultaneous optimization of several response variables," Journal of Quality Technology, vol. 12, no. 4, pp. 214-219, 1980.

[68] R. G. Robinson and M. M. Allam, "Effect of clay mineralogy on coefficient of consolidation," Clays and Clay Minerals, vol. 46, no. 5, pp. 596-600, 1998.

[69] A. K. Mishra, M. Ohtsubo, L. Y. Li, and T. Higashi, "Influence of the bentonite on the consolidation behaviour of soilbentonite mixtures," Carbonates and Evaporites, vol. 25, no. 1, pp. 43-49, 2010.

[70] I. Akinwumi, P. Awoyera, O. Olofinnade, A. Busari, and M. Okotie, "Rice husk as a concrete constituent: workability, water absorption and strength of the concrete," Asian Journal of Civil Engineering, vol. 17, no. 7, pp. 887-898, 2016.

[71] A. M. Rajabi and S. B. Ardakani, "Effects of natural-zeolite additive on mechanical and physicochemical properties of clayey soils," Journal of Materials in Civil Engineering, vol. 32, no. 10, Article ID 04020306, 2020.

[72] Q. Wang, Y. J. Cui, A. M. Tang, L. X. Ling, and Y. W. Min, "Time- and density-dependent microstructure features of compacted bentonite," Soils and Foundations, vol. 54, no. 4, pp. 657-666, 2014.

[73] S. Nayak and H. K. Preetham, "Effect of drying temperature and rewetting on the engineering properties of marine clay," Transportation Infrastructure Geotechnology, vol. 7, no. 4, pp. 517-534, 2020.
[74] G. Rajasekaran and S. N. Rao, "Lime stabilization technique for the improvement of marine clay," Soils and Foundations, vol. 37, no. 2, pp. 97-104, 1997.

[75] A. A. A. Rawas and M. F. Goosen, Expansive Soils: Recent Advances in Characterization and Treatment, Taylor \& Francis, Oxfordshire UK, 2006.

[76] N. A. R. A. Hadi, H. N. Khoury, and M. R. Suliman, "Utilization of bituminous limestone ash from EL-LAJJUN area for engineering applications," Acta Geotechnica, vol. 3, no. 2, pp. 139-151, 2008. 